\title{
The impact of conservatism and secrecy on the IFRS interpretation: The case of Tunisia and Egypt
}

\author{
Dr. Jihen Eljammi, IHEC Carthage , LIGUE ISCAE - Manouba \\ Jihen.eljammi@yahoo.com \\ Prof. Salma Damak-Ayadi, IHEC Carthage , LIGUE ISCAE - Manouba \\ salmadamak@yahoo.fr
}

Prof. Khaled Hussainey, Portsmouth University- UK

khaled.hussainey@port.ac.uk 


\begin{abstract}
Purpose: The effect of culture, through the accounting values of conservatism and secrecy, on accounting judgments is an area of research extensively studied in developed countries. However, little research has focused on this issue in developing countries, specifically Arab countries. Thus, this study tries to fill this gap by investigating the impact of the combined effect of the culture/accounting dimensions on the interpretation of the probability expressions used in the IAS/IFRSs in two North African/Arab countries: Tunisia and Egypt.

Approach: At the first place, this study determines the Hofstede's cultural index scores for Tunisia, ignored in his original model, and updates those related to Egypt, which provides a more relevant understanding of the cultural effect. Then, the study relies on the Hofsede/Gray cultural accounting model in order to examine the extent to which the accounting values of conservatism and secrecy may affect the recognition of the increase and the decrease of income, and the disclosure of this information in the financial statements by postgraduate accounting student in both countries.

Findings: The results provide evidence of the generalizability of Gray\&\#39;s conservatism hypothesis in the North African/Arab countries (i.e., Tunisia and Egypt), at least in the context of income recognition. Moreover, the findings demonstrate that culture, through its influence on the accounting value of secrecy, affects the interpretation of probability expressions used in the IFRSs to establish disclosures.

Implications and limitations: This study calls for more attention from the standard setters to provide further guidance related to the consistent and accurate numerical value that needs to be assigned to the probability expressions in order to reduce the ambiguity related to their interpretation. The IASB should pay greater attention to the use of vague PE in developing the IFRSs in order to promote the true comparability of financial reporting worldwide. As any research, this study implies certain limitations specifically related to the sample selection, sample size which may affect the generalizability of the results. Thus, future research may rely on a larger sample combining and cover other culture areas.

Originality: This study might be the first one that investigates the issue of the IFRS interpretation in two Arab countries: Tunisia and Egypt. It also provides an original investigation of the cultural effect on accounting judgments based on the actualized Hofstede's cultural indexes.
\end{abstract}

Key-words: Cultural values, conservatism secrecy, probability expressions, IFRS interpretation, Tunisia, Egypt. 


\section{Introduction}

Since its establishment in 1973, the international accounting standards board (IASB) has set up a general target that is to improve the quality of financial reporting across countries and to increase the transparency and comparability in the resultant financial statements. This objective was maintained through the development of the international accounting standards (IAS) published until 2001 and the international financial reporting standards (IFRS) published after 2001, which claimed to be high quality accounting standards that are eligible to be applied in any country across the globe. The IAS/IFRS are meant to improve the efficiency and accountability of the international financial markets and to increase the trust and the financial stability in the global economy. The IFRS organization has completed profiles for approximately 166 jurisdictions (ias-plus, 2020) which have abandoned their national accounting standards and moved to the international accounting system in order to meet the advantages offered by their application.

The Securities and Exchange Commission (SEC) issued a 'concept release' to verify the compliance with the IFRS among jurisdictions, and to confirm their rigorous and consistent application by the preparers and the stock exchange regulator. These elements seem to be beyond the control of the IASB and remain within the national accounting bodies and the professional organizations in each country. Therefore, it is crucial to understand the process of the IFRS interpretation and application in each national context, taking into consideration the cultural impact on this particular issue (Alibhai and Johnstone, 2019), and confirming the substantial association between culture and the international compliance with the IFRS (Nalukenge et al., 2018).

Despite the significant efforts undertaken to improve the quality of international financial reporting and the financial statements comparability across countries, considerable diversity still remains in the context of the IFRS interpretation, which may impede the process of the international accounting harmonization (Tsakumis, 2007). Actually, these accounting standards extensively use the probability expressions (PE) such as 'probable' and 'likely' as thresholds for recognitions and disclosure items that are covered with uncertainty, which may engender different interpretations of the accounting practitioners (Doupnick and Riccio, 2006).

Mainly, this issue is particularly addressed in the context of the international financial reporting interpretation committee (IFRIC) and the standards interpretation committee (SIC) standards, 
which offer broader explanations on certain accounting treatments that are claimed to be complex, vague and difficult for application by the IFRS users (Doupnick and Richter, 2003).

Actually, the issue of uncertainty that is described in certain standards using the PE presents a considerable ambiguity, and this called for a significant explanation from the IFRIC and SIC in order to reduce this ambiguity and provide a broader clarification for a proper interpretation and application of certain standards. For instance, in June 2017, the IASB published the IFRIC 23: 'Uncertainty over income tax treatment' to clarify the accounting treatment for uncertainties in income taxes under IAS12. Indeed, this particular standard includes a significant number of PE, namely: 'probable', 'no longer probable', 'expected', 'unlikely', 'usually' and 'often'. The interpretation of such standard with an extensive use of PE that are employed for the treatment of income tax recognition and disclosure creates a considerable diversity in its application across countries where accounting practitioners differently appraise its content enveloped with a major uncertainty margin. As a reply to this complexity, the IFRIC 23 provided further explanations of the sections related to the probable determination of the taxable profit, tax bases, unused tax losses, unused tax credits and tax rates in order to reduce the ambiguity related to its application ${ }^{1}$. Even though this particular standard was issued to limit the ambiguity related to the IAS12 application, several other standards using a considerable number of PE (e.g., IAS 37, IAS11) still imbue certain difficulties with regards to their interpretation, as they include PE that make its application inconsistent among practitioners from different cultures, especially with the restricted guidance on how to interpret them (Du et al., 2016).

Economic and environmental factors, including the national culture, play a critical role in the IFRS implementation process. These factors need to be considered by all countries worldwide that are planning to adopt the IFRS (Nurunnabi et al., 2020).

\footnotetext{
${ }^{1}$ An entity has to consider whether it is probable that the relevant authority will accept each tax treatment, or group of tax treatments, that it used or plans to use in its income tax filing.

If the entity concludes that it is probable that a particular tax treatment is accepted, the entity has to determine taxable profit (tax loss), tax bases, unused tax losses, unused tax credits or tax rates consistently with the tax treatment included in its income tax filings. If the entity concludes that it is not probable that a particular tax treatment is accepted, the entity has to use the most likely amount or the expected value of the tax treatment when determining taxable profit (tax loss), tax bases, unused tax losses, unused tax credits and tax rates.

The decision should be based on which method provides better predictions of the resolution of the uncertainty (IFRIC23, 2017).
} 
It is then claimed that one major cause of the existing diversity in the IFRS interpretation is Culture, which is defined by Hofstede $(1980,2010)$ as: '...the collective programming of the minds that distinguishes a group or category of people from another. Hence, a great number of studies have been undertaken in different countries in order to examine the effect of the cultural backgrounds on the interpretation of the probability expression which is extensively used in the IAS/IFRS. The results of these particular studies prove to have had a considerable effect of the cultural factor on the interpretation of these PE (e.g., Simon, 2002; Doupnik and Richter, 2003; Doupnik and Riccio, 2006, Du and Stevens, 2014), which may affect the interpretation and the application of the whole standard and, consequently obstruct the consistent application of the IFRS across countries and obstruct the international accounting harmonization process.

Moreover, there is a general consensus that accounting cannot be a "culture free" concept (Gray, 1988; Perera, 1989). Moreover, extensive research is undertaken in different parts of the world in order to examine the extent to which Hofstede's original cultural dimensions (i.e., uncertainty violence, power distance, masculinity and individualism) affect the application and interpretation of the IFRS across countries. These cultural dimensions are often studied in association with Gray's (1988) accounting values that are claimed to characterize the accounting practices (i.e., conservatism, secrecy, professionalism and uniformity) and shape countries' accounting systems. Thus, in the context of comparing the accounting decisions that have been performed based on the same accounting rules in different countries, the findings of this stream of research prove that the application of the IAS/IFRS is, indeed, affected by the cultural values of practitioners from different national backgrounds. For instance, Husssein (1996), Iskander \& Pourjalali (2000), Chaminade \& Johanson (2003), Gruning (2007) and Tsakumis (2007) study the effect of culture on different aspects of accounting practices (i.e., corporate disclosure, accounting system development; budgeting, contingencies recognition and disclosure, intellectual capital). Furthermore, Khlif (2016) specifies four main accounting research topics that have been studied with relation to Hofstede`s cultural values namely, reporting policy, auditing, taxation and miscellaneous accounting. This may give evidence of the effect of the cultural attributes on the financial reporting practices supporting the suggestion of the Hofstede/Gray cultural accounting association, by proving that the quality of financial reporting cannot be culturally free (Hashim, 
2012), and implying that countries' cultures have become progressively recognised as a critical aspect that shapes its accounting practice (Dowa et al., 2017).

Accordingly, this study's major contribution is the fact that it presents a significant complement to the existing mainstream of research that are discussing the relationship between culture and financial reporting decisions in a context that is almost neglected (i.e., North-African/Arab countries). Basically, the majority of the previous studies that are investigating this issue have focused on culture areas that are already categorized in Hofstede studies by putting forward a country grouping according to the different levels of the cultural values. Indeed, this classification includes several culture areas; however certain countries are discarded from this grouping such as Tunisia, Bolivia. Thus, this study offers specific culture scores for every cultural value for Tunisia, and an updated one for Egypt (i.e., the available scores date since 2010). These culture scores/indexes are then used to evaluate the accounting decision making undertaken by the participants in the research survey.

Nowadays, a major methodology problem persists for researchers working on the Tunisian context in various fields such as marketing (e.g., Abbes, Mouelhi, and Hallem, 2017; Besbes et al., 2016), management (e.g. Khanchel and Ben Kahla, 2018; Riahi, 2017) and accounting (e.g. Khlif, 2016; Ben Salem, Damak-Ayadi, and Saïhi, 2017), when they try to explain certain concepts based on national culture.

To overcome this deficiency, while relying on Hofstede's cultural model, some researchers have relied on other methods to detect the particularities of the Tunisian culture (e.g. Lassoued, 2001, 2008; Smida and Latiri , 2004; Ben Rejeb et al., 2006; Dakhli, 2009; Soyah and Magroun, 2004; El Akremi et al., 2007; Ouaness, 2011 ). Through their studies, they contributed to the failure of the idea of a united Arab culture.

Hence, this study's approach intends to avoid the simple assignment of the Arab world's cultural indexes to Tunisia, as it may present certain differences from the whole group. So, it is more relevant to attribute to each country its specific culture indexes in order to provide an accurate analysis thereafter. This is consistent with Hofstede's progressive approach in updating and improving his culture dimensions. In fact, in his original study (1980), the author provides a culture classification by gathering the countries that present approximate cultural tendencies (i.e., 
the Arab world, the Near Eastern, the Anglo), and which share the same scores for the four original cultural values. Subsequently, in his book entitled: Cultures and Organizations: Software of the minds (2010), this country grouping is disseminated by attributing to each country its specific culture indexes. This progression is due to the significant historical, economic and political shifts that happened around the globe, and which altered the obsolete country clusters (Rotondo et al, 1997). Meanwhile, even in his updated versions of the culturecountry classification, Tunisia still does not exist in his world mapping. This approach triggered our curiosity to determine this Arab country's cultural indexes in order to place it in this world categorization. Moreover, as an Arab country, we would verify whether Tunisia conforms in belonging to the Arab world cluster by comparing its cultural values to an Arab country that already exists in this cluster, Egypt. Furthermore, having specific culture indexes for each of the countries in this study is crucial in giving our analysis of the effect of culture on accounting decisions more relevance. Indeed, it prevents the allocation of the Arab world's outdated cultural indexes to a specific country which may have certain particularities that probably affect the culture indexes and that create shifts on the levels of the cultural values (e.g., El Akermi et al., 2007; Dakhli, 2009. This irrelevant approach may create a misleading assumption related to generalizing the findings of a specific culture to other cultures. This same approach was undertaken by previous studies such as Fisher and Al-issa (2012) for seven six Arab countries (i.e., UAE, Egypt, Saudi Arabia, Syria, Lebanon, Palestine), Mansour et al. (2019) for Sudan and Alkallani and Azzam (2012) for Jordan, who re-determine specific culture scores for the studied countries for more updated and accurate analysis of the discussed issues.

Therefore, the objective of this study is to examine the extent to which culture, through the accounting values of conservatism and secrecy, affects the interpretation of the PE in the IAS/IFRS in two North African and Arab countries, namely Tunisia and Egypt. In particular, it examines its eventual effect on the Tunisian and Egyptian post-graduate accounting students' interpretation of the PE used as recognition and disclosure thresholds in selected IAS/IFRSs whereas the participants are asked to assign a numerical probability to these uncertainty terms in order to assess to extent of the consistency in the decision making emanating from respondents with different cultural backgrounds 


\section{Review of the Hofstede-Gray theoretical framework and its empirical tests}

The IASB acquired greater legitimacy and stature when the European Union (EU) decided to require that all listed companies have to prepare consolidated accounts based on the International Financial Reporting Standards (IFRS) beginning in 2005 (Larson and Street, 2004). As the processes of globalization have become increasingly evident, there have also been calls for International Accounting Harmonization (IAH). At the same time, there have been impediments in the path towards achieving IAH, and some of them are the cultural and economic differences among countries (Baker and Barbu, 2007).

May (1938) argues that the issue of "accounting uniformity" has received broad attention from regulating bodies, academicians and professional accountants. He confidently admits that further progress in accounting harmonization can be made through cautious cooperation between different partners who are interested in the matter. However, he argues that a clear understanding of the significance and limitation of accounting harmonization is indispensable before an attempt for uniformity can take place. For instance, Wilkinson (1969) is probably one of the initial studies discussing the advantages and challenges on harmonizing the international accounting practices. Even though he thinks that the differences in accounting practices worldwide are of such an amount as to inhibit severely the communication function that financial statements are meant to perform. Perhaps one of the major concerns in initiating accounting harmonization is achieving one of the qualities of accounting information which is 'comparability'. This quality requires that, in order to be both useful and relevant, accounting information must be comparable with one business entity to another. In fact, the harmonization of accounting standards is in fact being achieved with the widespread adoption of the International Financial Reporting Standards (IFRS). Nevertheless, the idea persists that the introduction of similar accounting standards could fail to harmonize reported information because of the institutional differences (i.e., cultural, legal, tax) among countries and the incentives those differences create among the preparers of financial reports (Leuz, 2010). In fact, the different tax orientation of national accounting systems, the complicated nature of a particular IFRS, lack of staff training and guidance on the first-time application of the IFRS, an underdeveloped national capital market, the lack of strong professional accountancy bodies in some countries, the differences in political and economic 
systems, and cultural resistance to the change in national accounting systems, will all hinder the process of IAH. Emenyonu and Gray (2002) argue that IHA is still a vague objective, thus they examined the results of the efforts made, so far, to reduce the diversity in accounting practices internationally. An evaluation of the substantial changes that have happened over the 20 years period from 1971/72 to 1991/92 shows that while progress has been made in some respects, international accounting harmonization has remained a vague goal. Therefore, obstacles remain in the path of IAH that obstruct the process of bringing the financial reporting practices of different countries into line.

\subsection{Theory of the influence of culture on accounting}

This study uses the Hofstede-Gray cultural accounting model that explains the diversity in accounting systems and practices internationally. Basically, this model is a combination of the original cultural theory, as proposed by Hofstede (1980) that is dividing the world into culture areas based on different cultural dimensions, and Gray's (1988) accounting values. This combination is integrated into four hypothesized relationships that explain the diversity in accounting practices, internationally based on the national cultural factors. Different definitions of culture have been proposed in the literature. According to Adler (2002), it is the compilation of concepts, shared values and common rules of behavior in any group or society (Adler, 2002, p.16). It is then considered as another designation of the national identity (Najm, 2002, p. 423). Meanwhile, the most commonly used definition of culture is the one proposed by Hofstede (1991, p.5) as "... a collective programming of the mind that distinguishes the members of one group or category of people from another". Since then, culture has been applied in multiple research fields in trying to explain the differences in individuals' behavior as it shapes people's mode of thinking as reflected in their acts.

\section{Hofstede's cultural dimensions}

Hofstede's cultural model is a framework for cross-cultural dimensions that shape the countries' value construct. Hofstede initially developed this theory based on a large survey of IBM 
employees in 40 countries between 1967 and 1973. Using factor analysis, the original model resulted into four cultural dimensions defined by Hofstede (1980) as follows:

- Power distance: 'is described as the extent to which the less powerful members of institutions and organizations within a society expect and accept that power is distributed unequally'

- Individualism vs. Collectivism: 'Individualism is the opposite of Collectivism. Individualism stands for a society in which the ties between individuals are loose: a person is expected to look after himself or herself and his or her immediate family only. Collectivism stands for a society in which people from birth onwards are integrated into strong, cohesive in-groups, which continue to protect them throughout their lifetime in exchange for unquestioning loyalty.'

- Masculinity vs. Femininity: 'Masculinity is the opposite of Femininity. Masculinity stands for a society in which social gender roles are clearly distinct: men are supposed to be assertive, tough, and focused on material success; women are supposed to be more modest, tender, and concerned with the quality of life. Femininity stands for a society in which social gender roles overlap: both men and women are supposed to be modest, tender, and concerned with the quality of life.'

- Uncertainty avoidance: 'Uncertainty Avoidance is defined as the extent to which the members of institutions and organizations within a society feel threatened by uncertain, unknown, ambiguous, or unstructured situations.'

Later on, the original survey (Value Survey Module-VSM 1982) was refined to build up more developed constructs ${ }^{2}$ proposing two additional cultural dimensions. The fifth cultural value is Long vs. short Term Orientation, and that was created based on the Chinese Value Survey (CVS) carried out in 1994 by M.Minkov surveying students in 24 countries. The sixth value is Indulgence vs. Self Restraint (Hofstede and Bond, 2010) which was a result of the World Value Survey (WVS) undertaken in up to 81 countries. These two additional dimensions were defined by Hofstede (2010) as follows:

\footnotetext{
${ }^{2}$ The refinement of the VSM resulted into several developed versions : VSM 1983, VSM 1994 and VSM2013. Each version was characterized by a different number and order of the questions. Certain questions were kept and others replaced in order to attain a more accurate representation of the cultural background. Moreover, the Chinese value survey was distributed in over 24 countries and resulted in the fifth cultural dimensions and the World value survey
} 
-Long vs. Short Term Orientation: 'Long Term Orientation is the opposite of Short Term Orientation. Long Term Orientation stands for a society which fosters virtues oriented towards future rewards, in particular adaptation, perseverance and thrift. Short Term orientation stands for a society which fosters virtues related to the past and present, in particular respect for tradition, preservation of "face", and fulfilling social obligations.'

- Indulgence versus Restraint: 'Indulgence stands for a society which allows relatively free gratification of some desires and feelings, especially those that have to do with leisure, merrymaking with friends, spending, consumption and sex. Its opposite pole, Restraint, stands for a society which controls such gratification, and where people feel less able to enjoy their lives.

The VSM is composed of 24 content questions whereas each group of them are supposed to compute with one of the six cultural dimensions which deal with key issues in national cultural research (Hofstede and Minkov, 2010) as defined above ${ }^{3}$ (i.e., the scores are determined on the basis of four questions per dimension). It also includes six demographic questions related to the respondents' age, gender, nationality, occupation and education which give an overview of the sample's social characteristics. The ultimate objective of this questionnaire is to compare cultural characteristics if there are similar respondents within different countries, whereas individual countries' scores are meaningless. In order to have a good use of the VSM, Hofstede has developed a manual which guides researchers in determining their related culture scores in different national settings ${ }^{4}$.

Meanwhile, Gray (1988) has developed a theoretical model for accounting research which relates Hofstede's initial cultural values (i.e., power distance, uncertainty avoidance, masculinity/femininity and individualism/collectivism) to his proposed accounting values (i.e., conservatism, secrecy, professionalism and uniformity). Moreover, Gray posits that a country's cultural characteristics affect the accountants' interpretation and application of accounting rules, and thus shape its accounting system. These accounting dimensions are derived from the literature and its practice and are defined by Gray (1988, p.496) as follows:

\footnotetext{
${ }^{3}$ For example, to compute for the Power Distance score, the researcher needs to use the mean scores for questions 2,7, 20 and 23 from VSM2013.

${ }^{4}$ Available at geert-hofstede.com
} 
-Conservatism vs. Optimism: a preference for a cautious approach to measurement so as to cope with the uncertainty of future events as opposed to a more optimistic, laissez-faire, risk-taking approach.

- Secrecy vs. Transparency: a preference for confidentiality and the restriction of disclosure of information about the business only to those who are closely involved with its management and financing, as opposed to a more transparent, open and publicly accountable approach.

- Professionalism vs. Statutory Control: a preference for the exercise of professional judgment and the maintenance of professional self-regulation as opposed to compliance with prescriptive legal requirements and statutory control.

-Uniformity vs. Flexibility: a preference for the enforcement of uniform accounting practices between companies and for the consistent use of such practices over time as opposed to flexibility in accordance with the perceived circumstances of individual companies.

Consequently, Gray (1988) proposes four hypotheses incorporating the cultural and accounting dimensions in the same construction.

-Conservatism hypothesis: The higher a country ranks in terms of uncertainty avoidance and the lower it ranks in terms of individualism and masculinity then the more likely it is to rank highly in terms of conservatism.

-Secrecy hypothesis: The higher a country ranks in terms of uncertainty avoidance and power distance and the lower it ranks in terms of individualism and masculinity then the more likely it is to rank highly in terms of secrecy.

-Professionalism hypothesis: The higher a country ranks in terms of individualism and the lower it ranks in terms of uncertainty avoidance and power distance then the more likely it is to rank highly in terms of professionalism.

-Uniformity hypothesis: The higher a country ranks in terms of uncertainty avoidance and power distance and the lower it ranks in terms of individualism then the more likely it is to rank highly in terms of uniformity 
Gray (1988) proposed a theoretical model that is relating Hofstede's societal values to his accounting dimensions and explained how the latter impact the development of national accounting systems. This accounting cultural framework is considered as the most important structure that identifies how cultural values affect and shape accounting systems internationally as outlined in the next figure.

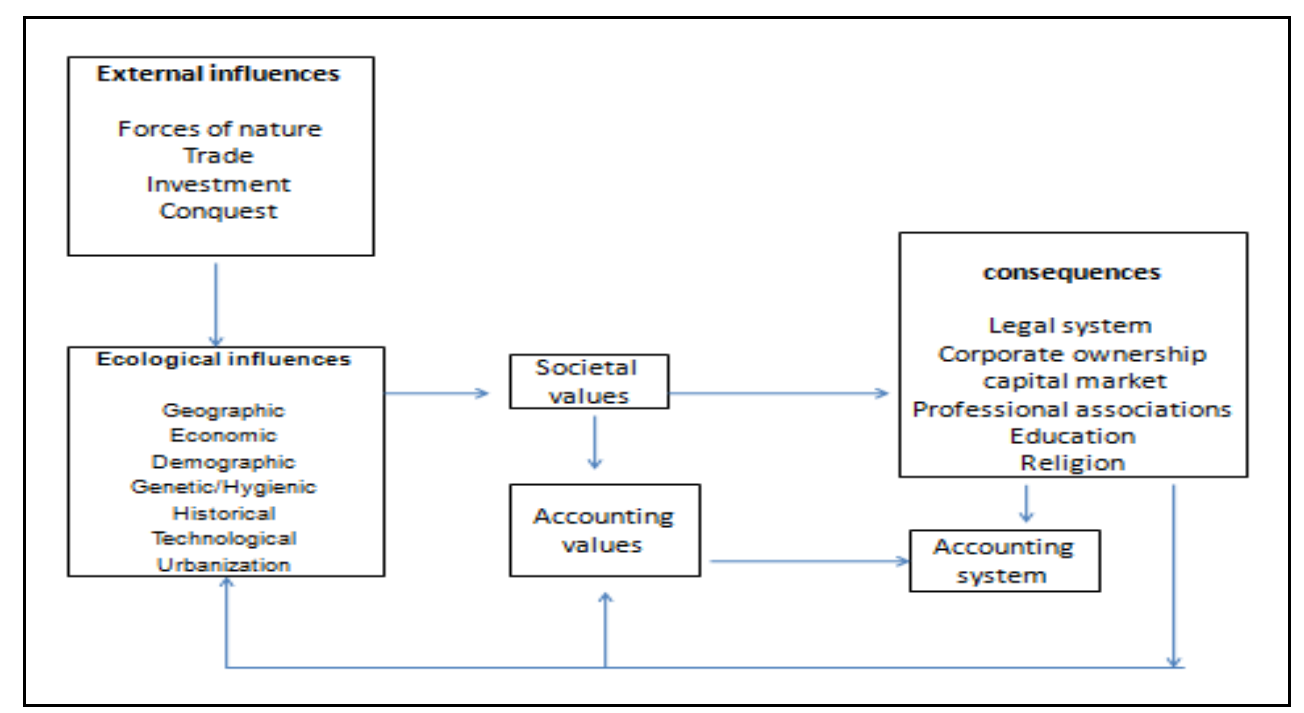

Figure 1: Culture, Societal Values and the Accounting Subculture (Gray, 1988)

It is worth mentioning that, despite all the criticism addressed to the Hofstede-Gray cultural accounting framework, culture/accounting dimensions are extensively used in the accounting research in order to explain the behavior of individuals involved in the accounting discipline at the international level (e.g., accounting students, professional accountants and standards setters) which includes the interpretation of accounting standards, accounting systems' choices and differences in financial reporting decisions.

It is also argued that Gray's secrecy hypotheses have been subject to more testing (e.g., Bavishi, 1993) as compared to the accounting value of conservatism (e.g., Eddie, 1990; Salter and Niswander, 1995). This may be due to the difficulty in developing a country-level measure of a financial reporting system attribute like conservatism. However, annual reports could be used relatively easier to develop disclosure measures because of available disclosure indicators (Tsakumis, 2007). 
Few studies have analyzed the relevance of the Hofstede cultural value in explaining accountants' behavior in Tunisia, such as Triki et al. (2012) who identify up-dated scores for Tunisia based on a sample of professional accountants which seem to reveal an accounting subculture that is quite high on masculinity, quite low on uncertainty avoidance, relatively high on power distance and relatively low on individualism. Besides, Bouderbela et al. (2020) empirically reproduce Hofstede's model in the Tunisian context, based on a sample of top managers of local companies, and find evidence that the Tunisian national culture has convincing properties that differentiate it from the transnational Arab culture. Moreover, among the studies exploring the impact of culture on managerial and accounting behaviors in the Egyptian context, Parnell and Hatem (1999) argue that the different cultural characteristics of American and Egyptian managers impact their behavioral management practices. This entails that the same management approaches are appraised differently in different cultural contexts. Based on the analysis of the accounting value of secrecy, Dahawy et al. (2002) draw on Hofstede`s (1980) theory along with its adaptation by Gray (1988) engendering a comprehensive model that is able to understand the possible resistance to the implementation of the IAS/IFRS in a developing country such Egypt. This resistance would engender a selective implementation of the international standards with a non-compliance with specific disclosure rules that might be incompatible with the secretive nature of the Egyptian society.

\subsection{Empirical tests of the cultural model}

The relationship between the cultural values and financial reporting systems is carried out at both the country and the individual levels. With regards to the first stream of research, various studies were undertaken in countries with different levels of development to investigate the influence of the cultural characteristics on the development of national accounting systems based on annual 
reports' data. Eddie (1990) conducted the first empirical test of Gray's framework by testing his four hypotheses and by relating Hofstede's cultural values to his accounting values. The study tests this theory by creating an index of accounting dimensions for thirteen Asian-pacific countries and then correlates them with Hofstede's cultural dimensions. The results confirm that the predicted signs of this alliance are validated. However, the accounting value constructs and their method of measurement are not accurate enough and then, these findings are quickly dismissed (Finch, 2009). Later, Chanchani and Willet (2004) investigate the relevance of this framework in New Zealand and India. Overall, this study finds evidence of the usefulness of Gray's framework especially with the finding that professionalism appeared as the most coherent accounting value. The elements of the uniformity construct seemed to attract aspects of secrecy, as originally conceptualized, and indicate that the value of secrecy could be contained within a broader accounting value construct. Conservatism appeared to be split into two parts related to the sub-dimensions of disclosure and measurement.

Focusing on a single country`s data, Noravesh et al. (2007) examine the application of accounting standards and financial reporting practice in Iran for a period of ten years (19932002). The results confirm that more than one- half of Gray's hypotheses are relevant in the Iranian context. This provides evidence that Gray's model may not be valid for every society. This is consistent with prior studies that confirm a part of the hypotheses (e.g. Niswander and Salter, 1995; Jaggi \& Low, 2000; Noravesh et al., 2003). Many issues, such as the irregular development of accounting in Iran and the unsuitable application of accounting methods and procedures, which are common among developing countries, might be determinant factors explaining why several of Gray's hypotheses are not supported in this cultural context. However, based on Gray's framework, Iskander \& Pourjalali (2000) were able to analyse the role of culture on the development of accounting practices in the Malaysian context. Their study was based on an analysis of the effect of the substantial changes in the economy and culture in Malaysian accounting practices during the economic growth period from 1987 to 1997. They argued that cultural values during this period were ranked lower in collectivism, power distance, uncertainty avoidance and masculinity. In addition, their results regarding actual changes in accounting values support the suggestion of Gray (1988). In the same Asian context, Sudarwan and Fogarty (1996) perform a longitudinal study of a twelve years period (1981-1992) in order to empirically examine the relationship between culture and accounting development on Indonesia. The results provide evidence that out of Hofstede's five cultural values, three of them (i.e., power distance, uncertainty avoidance and individualism) are significantly related with one or more of Gray's accounting values In order to compare the cultural influences on financial reporting in the US and Netherlands, Husssein (1996) uses Hofstede's cultural framework to investigate whether culture has the same effect on the two countries' accounting development. The findings show 
that both countries share almost the same characteristics (i.e. in terms of high individualism, weak uncertainty avoidance, and small power distance) which explain and fit both countries as free enterprise capitalist societies, and their values of an individual's interest. According to Ward and Lowe (2017) Hofstede's cultural dimensions assist in a better understanding of the differences among cultures, its potential impact on financial reporting, and consequently the comparability of financial statements prepared based on the IFRS. They prove that two of Hofstede's cultural dimensions (i.e., power distance and individualism) significantly influence countries' acceptance of IFRS. All in all, despite all the critiques developed in the previous literature against the Hosted cultural model, it did not lose its attractiveness and multiple replications (Lee and Herold, 2018).

As this study focuses on the cultural influence on accounting judgments in two developing countries, the previous research undertaken in the North-African/Arab culture areas based on the Hofstede-Gray culture-accounting theoretical model is reviewed. Indeed, an understanding of the cultural similarities/differences among nations could be identified and would be significant in the process of harmonizing financial reporting standards.

The relevance of culture in the application of accounting rules is a contemporary issue discussed at the international level, and specifically in Arab countries. In fact, Askary et al. (2008) examine the influence of cultural values on accounting uniformity and consistency among Arabic nations. Their study uses a combination of survey and analysis of 132 listed companies' (excluding banks and financial institutions) annual reports and other published data in six countries namely, Bahrain, Jordan, Kuwait, Oman, Qatar and Saudi Arabia. Their findings are basically in support of the Hofstede-Gray hypothesis of accounting uniformity in Arab countries.

With a particular focus on studies that examine the cultural impact on accounting at the individual level, it is evident that they put a great emphasis on accountants' professional judgments, interpretation and application of accounting rules, with a particular stress on the national cultural characteristics. For instance, Tsakumis (2007) who chose Greece and the US for the study tries to investigate the influence of culture on American and Greek accountants' interpretation and application of the IAS extracts. His approach was applied with a specific investigation of Gray's (1988) accounting values of conservatism and secrecy, which are able to identify issues that affect countries' accounting systems. The results do not reveal any significant difference between Greek and American accountants' recognition decisions, which is good news 
for an international harmonization of accounting. However, it seems that the value of secrecy tends to affect the disclosure decisions undertaken on the basis of the same accounting standards.

These findings raise the question of whether a common set of accounting standards would be applied consistently across cultures, especially, when this standard requires both recognition and disclosure judgments. This general inquiry relates to this study's objective that aims to find out whether common accounting rules (IFRS) could be applied consistently in the Tunisian and Egyptian contexts as a step towards the international harmonization of accounting, despite the cultural differences that may exist between the two countries.

\subsection{The effect of culture on the IFRS interpretation}

Prior studies have mainly examined the numerical interpretation of the probability expressions (PE) used in the Statement of Financial Accounting Standards (SFAS) No.5: Accounting for Contingencies 5, published by the Financial Accounting Standards Board (FASB) in 1975. Thus, the subsequent terms and expressions are the most studied in the literature that reassess the interpretation of the PE in accounting and auditing settings: "remote", "reasonably possible" and “probable" (e.g. Jiambalvo and Wilner, 1985; Chesley, 1986; Harrison and Tomassini, 1989; Reimers, 1992; Amer et al., 1994; 1995; Laswad and Mak, 1997; Aharony and Dotan, 2004; Doupnik and Riccio, 2006).

SFAS No.5 establishes standards of financial accounting and reporting for loss contingencies. It requires accrual by a charge to income (and disclosure) for an estimated loss from a loss contingency if two conditions are met: (a) information available prior to the issuance of the financial statements indicates that it is probable that an asset had been impaired or a liability had

been incurred at the date of the financial statements, and (b) the amount of loss can be reasonably estimated. In accounting for gain contingencies under Accounting Research Bulletin No.50, contingencies, remains unchanged, and they are recognized when realized (FASB, 2013). The international accounting standards issued by the IASB (IAS/IFRS) are developed with the objective of enhancing the international comparability of financial statements and they extensively use the as PE mentioned in table 1. 
Table 1. French translation of the probability expressions used in the research instrument

\begin{tabular}{|l|l|}
\hline English version of the PE & French version of the PE \\
\hline Probable & Probable \\
\hline Reasonable assurance & Assurance raisonnable \\
\hline Reasonable certainty & Certitude raisonnable \\
\hline No longer probable & N'est pas probable \\
\hline More likely & Plus probable qu'improbable \\
\hline Virtually certain & Quasiment certain \\
\hline Remote & N'est pas probable \\
\hline
\end{tabular}

These terms and expressions are used in those standards to establish the recognition and disclosure criteria for accounting elements (i.e. financial statement items) such as assets (e.g. IAS 12), revenues, expenses and losses (e.g. IAS 13) and liabilities (e.g. IAS 37); as well as to establish the thresholds for derecognizing assets (e.g. IAS 12).

This study focuses on the interpretation of postgraduate accounting students of the PE included in selected IAS/IFRS. In particular, it looks at the impact of specific cultural attributes, such as conservatism and secrecy, on these interpretations whereby the participants, from different cultural backgrounds, would differently give numerical interpretations to these expressions. It is then important to look at the levels of these two accounting values determined earlier by Gray (1988), in order to consider the direction of their effect on the PE interpretation.

Due to the extensive use of the uncertainty expressions, accounting scholars have critically evaluated their possible effect on accounting decision making (Kinsey et al., 2018). Basically, PE are varied and frequent as they are present in a considerable number of IAS/IFRS and they are formed in both positive and negative forms (i.e., expected and unexpected). These are in addition to those which assume both positive and negative forms (i.e. probable), which are the most frequently used in the IAS/IFRS (Doupnik and Richter, 2004). In addition, the occurrence of these expressions is varied since one standard could contain more than one probability expression (e.g., IAS 37, IFRS7), which would affect the outcome of their interpretation. It is also obvious from this classification that almost all standards include PE, and some of them are stated in the concepts, while others are present in the recognition, measurement and disclosure 
criteria (Tsakumis, 2007). The first may have an indirect influence on the interpretation and application of the IAS/IFRS, and those used in the recognition, measurement and disclosure criteria may have a significant and direct impact on the interpretation and application of accounting standards (Teixeira and Fialho, 2009), and which are used in the current study's research instrument

The subject of the use of words versus numbers in the communication of probability in accounting and auditing is crucial, not only for those working in the field, but also for the researchers, teachers or students. Therefore, it is necessary to further investigate this issue, using companies and professional organizations, thus shifting from a theoretical standpoint to a more practical approach (Chesley, 1986).

Among the studies that have been undertaken in Europe, Simon (2002) represents the first research on the interpretation of PE used in accounting standards by British professional accountants. The thirty terms and expressions examined in that study fairly reflect the diversity and complexity of PE used in this context. The results show that while many probability expressions seem to have a similar meaning and a high degree of communication efficiency, several have low communication efficiency. The study's policy implications engage a reconsideration of the use of PE with low communication efficiency, and the adoption of wellunderstood probability expressions with high communication efficiency in order to enhance the appropriate understanding of the PE that would engender a better appraisal and interpretation of the whole standard.

Cable and Patel (2000) and Chand et al. (2009) argue that countries programming to adopt the IFRS need to educate their future accounting practitioners to be able to interpret and apply the IFRS in a consistent and relevant manner. This is by examining the effect of the national cultural characteristics and education on the judgments of Chinese and Australian undergraduate accounting students in Australia in an attempt to investigate the extent to which culture influences the students' interpretation and application of uncertainty expression used for the recognition and disclosure requirements in the IFRS. The values obtained by Chand et al. (2009) on the cultural dimensions of uncertainty avoidance, power distance, masculinity, individualism and long-term orientation prove that Chinese students show more conservatism and secrecy than Australian students due to different national cultural influences. Thus, standard setters should 
pay a greater attention to cultural influence at the international levels, which could cause different interpretations and application of the same accounting standard, which proves the influence of culture on individuals' professional judgments.

A special attention is paid to Gray's accounting value of conservatism by Doupnik and Richter (2003) who investigate the interaction among this value and the context in which probability expressions, included in many accounting standards, were used, and the way accountants from different cultural backgrounds interpret some of them. Their study addresses the issue of whether the interpretation of the probability expressions in the IFRS varies among German and U.S accountants. Based on the Hofstede-Gray framework of how national culture affects accounting values, they suppose that different levels of conservatism of the two selected countries would systematically cause a variation in the interpretations of the selected verbal probability. Their findings illustrate considerable differences between the selected samples with the German participants being more conservative than their American counterpart. Later, Doupnik and Riccio (2006) replicated the same study, but in different countries by incorporating the Latin culture area in the comparison (i.e. Brazil vs. the US). They obtained partial support for the conservatism and recognition hypothesis and stronger support of the hypothesis related to secrecy and disclosure.

These findings are partially evidenced by Haller and Wehrefritz (2014) comparing German and British accountants' judgements. Their results give some evidence of the international influence on the IFRS explicit options' interpretation. The ongoing concern about the financial statements' comparability and the actual debate of whether a common set of accounting standards could be interpreted consistently by accountants from different countries have triggered the attention of different scholars to gather some international evidence about the impact that cultural attributes may have on financial reporting. For instance, in an attempt to evaluate the accurate understanding and interpretation of the verbal probability expressions (VPE) by Chinese accounting professionals and students, Tang and Yang (2016) examine whether the VPE in principles-based accounting standards are understood and interpreted consistently. Data is gathered from auditors working in Chinese public accounting firms, and Chinese accounting students and the results specify that Chinese auditors exhibit a higher degree of consensus in their VPE interpretations than the preparer and student. 
Recently, Kolesnik et al. (2019) investigate whether British and Polish accountants interpret differently the same IFRS excerpts including probability expressions. The results give evidence of a different interpretation undertaken by the Polish sample, which is more attached to the prudence principle affecting their accounting judgments. In an attempt to compare the Chinese and British accountants' interpretation of the IFRS, Guermazi and Halioui (2019) investigate the combined effect of language-culture on accounting judgments and give evidence of their reflection on the directionality of the uncertainty expressions. They argue that these expressions might reduce the judgment bias effect by referring to making a professional judgment in the participants' foreign languages (i.e., Chinese and English). In the same context, Zhang et.al (2019) outline the most crucial issue related to uncertainty expressions interpretation and the associated personal bias contextualized in the behavioral-psychology literature. Thus, the authors recommend a solution to reduce the potential impact of these expressions on accounting judgments through the association of the verbal and the numerical measures for the communication of objective accounting information. This combination of numbers/expressions may enhance their communication efficiency and reduce the personal subjective assessment affected by several factors, including culture.

These results raise the question of whether a common set of accounting standards would be applied consistently across cultures, especially, when this standard requires both recognition and disclosure judgments. This relates to this study's objective that aims to find out the extent to which the same accounting rules could be applied consistently in the Tunisian and Egyptian contexts as a step towards the international harmonization of accounting, taking into account the cultural specificities of the two countries.

From the above literature review, it is obvious that various studies have investigated the impact of culture on accounting practices related to different contexts, where cultural diversity engenders different accounting practices between the selected countries. Almost all of these studies examined this issue with particular emphasis on Hofstede-Gray's cultural-accounting framework. However, the reviewed papers do not include an investigation of the influence of culture on accounting practices in the selected North African and Arab countries in this study (Tunisia and Egypt), as was the case for the U.S and Greece (Tsakumis, 2007), or China, HongKong and Taiwan (Kung et al., 2008). In addition, Tunisia, as an Arab country, has not been 
subject to this kind of investigation unlike Egypt which was selected by Askary et al. (2008) in order to search for the impact of cultural values on accounting uniformity among Arabic nations. However, their sample did not include Tunisia or Egypt. Besides, most of the studies have chosen either two or more developed countries in order to investigate the relationship between culture and accounting practices (e.g., the U.S and Greece; Germany and Poland), or compared one developed country with less developed countries (e.g., New Zealand and India). Some studies have investigated the applicability of the cultural-accounting framework in only developing countries (e.g., Iran, Malaysia) but it seems that Tunisia has not been subject to this kind of examination in previous studies.

This study tries to fill the gap in the literature by investigating the cultural-accounting aspect in North-African/Arab countries. In fact, Deddoussis (2004) argues that less than one percent of the published comparative papers in a ten-year period between 1990 and 1999 focus on Arab countries, which creates a need to give more attention to this part of the world and to shed some light on the Arab world`s cultural characteristics that may explain certain accounting practices.

Accordingly, this study contributes to the existing literature by filling the above-mentioned gap at different levels. Initially, it investigates the effect of culture, through the accounting values of conservatism and secrecy, in a cultural context that has been overlooked in previous research in this area, namely the North-African region, and in particular the Arab countries, Tunisia and Egypt. This study also contributes to the literature by relying on Hofstede's cultural theory by determining updated culture indexes for Tunisia, which is an Arab country that is neglected in Hofstede's country classification (i.e., the Arab world grouping includes several Arab countries but disregards Tunisia).

Thus, future studies examining the effect of the cultural factor on any aspect of the accounting discipline may rely on these updated cultural scores which capture the national specificities of the studied country, instead of simply using the existing outdated Arab countries' indexes. 


\section{Research Design and hypothesis development}

\subsection{Hypotheses development}

Based on the Hofstede-Gray cultural accounting model, three hypotheses are developed in the context of this study, which focuses on the effect of conservatism and secrecy on the participants' interpretation of accounting standards (IAS/IFRS) including probability expressions (PE). These hypothesized relationships combine Hofstede's cultural dimensions (i.e., uncertainty avoidance, long term orientation, individualism and masculinity) and two of Gray's accounting values that are most related to accounting recognition and disclosure: conservatism and secrecy. The first two hypotheses are related to the accounting value of conservatism which assesses the accounting items' recognition and measurement. The third hypothesis is associated with the accounting value of secrecy related to the accounting information disclosure.

The first conservatism hypothesis implies that participants from a country characterised by a higher degree of conservatism (i.e., higher in terms of uncertainty avoidance and long term orientation and lower in terms of individualism and masculinity, according to Gray, 1988) are expected to assign a higher numerical probability to the items (in the context of an IAS/IFRS extract) that increase net income in order to avoid the recognition of this particular item than participants from a country with a lower level of conservatism (more optimistic than conservative) which reveals a more cautious approach to an accounting measurement. The second conservatism hypothesis entails that the participants from a country with a higher level of conservatism would assign a lower numerical probability to items (included in an IAS/IFRS extract) that decrease net income, than those participants from a country with a lower level of conservatism (more optimistic) in order to accelerate the recognition of that particular item.

The conservatism hypotheses are developed as follows:

H1: Participants in a country that ranks higher in terms of conservatism will assign a higher numerical probability to PE related to the recognition of items that increase net income than participants in a country that ranks lower in terms of conservatism. 
H2: Participants in a country that ranks higher in terms of conservatism will assign a lower numerical probability to PE related to the recognition of items that decrease net income than participants in a country that ranks lower in terms of conservatism.

The secrecy hypothesis proposes that the participants from a country with a higher level of secrecy (higher degree of uncertainty avoidance, power distance and long term orientation and lower in terms of individualism and masculinity, according to Gray; 1988) are expected to assign a higher numerical probability than participants from countries with lower levels of secrecy (i.e., with a more transparent approach) to items (included in certain IAS/IFRS extracts) related to the disclosure of information about the business (in the notes to the financial statement).

The secretive approach to accounting disclosure implies a preference for confidentiality with a restricted revelation of internal business information to the outsiders. The secrecy hypothesis is developed as follows:

H3: Participants in a country that ranks higher in terms of secrecy will assign a higher numerical probability to PE related to the disclosure of an item of information than participants in a country that ranks lower in terms of secrecy.

Few studies have re-analysed the relevance of the Hofstede cultural value in explaining accountants' behaviour in Tunisia such as Triki et al. (2012) who identified up-dated scores for Tunisia based on a sample of professional accountants which seem to reveal an accounting subculture that is quite high on masculinity, low on uncertainty avoidance, relatively high on power distance and relatively low on individualism. Moreover, among the studies that are exploring the impact of culture on managerial and accounting behaviors in the Egyptian context, Parnell and Hatem (1999) argue that the different cultural characteristics of American and Egyptian managers impact their behavioral management practices. This entails that the same management approaches are appraised differently in different cultural contexts. based on the analysis of the accounting value of secrecy. Dahawy et al. (2002) draw on Hofstede`s (1980) theory along with its adaptation by Gray (1988) engendering a comprehensive model that is able to understand possible resistance to the implementation of the IAS/IFRS in a developing country such as Egypt. This resistance would engender a selective implementation of the international standards 
with a non-compliance with specific disclosure rules that might be incompatible with the secretive nature of the Egyptian society.

The next figure outlines Gray's country classification of countries according to their levels of conservatism and secrecy which are claimed to be the most significant accounting values in relation to the accounting measurement and disclosure practices (Gray, 1988).

\begin{tabular}{|c|c|c|c|c|}
\hline Nordic & Latin American & Anglo & Germanic & \\
\hline $\begin{array}{l}\text { Netherlands, Norway, } \\
\text { Sweden, Denmark, Finland }\end{array}$ & $\begin{array}{l}\text { Elselvador, } \\
\text { Uruguay, } \\
\text { Colombile, }\end{array}$ & $\begin{array}{l}\text { Australia, Canada, Ireland, } \\
\text { New Zealand, South } \\
\text { Africa, United Kingdom, } \\
\text { United states }\end{array}$ & $\begin{array}{l}\text { Austria, } \\
\text { Switzerland }\end{array}$ & Germany, \\
\hline Near Eastern & Latin European & Far Eastern & & \\
\hline $\begin{array}{l}\text { Greece, Iran, Turkey_Arab } \\
\text { countries } \\
\text { (Egypt, Morocco, UAE, } \\
\text { Iraq, Oman, Kuwait, } \\
\text { Lebanon, Saudi Arabia, } \\
\text { Jordan, Libya, Syria, } \\
\text { Bahrain) }\end{array}$ & $\begin{array}{l}\text { Belgium, France, Italy, } \\
\text { Portugal, Spain }\end{array}$ & $\begin{array}{l}\text { Hong Kong, Indonesia, } \\
\text { Malaysia, } \\
\text { Singapore, } \\
\text { Thailippine, }\end{array}$ & & \\
\hline
\end{tabular}

\section{Figure 2. Hofstede model of countries' grouping in clusters}

The Arab countries' cluster is classed within the Near Eastern group including Greece, Iran and Turkey. This categorization is based on several environmental factors (e.g., Mueller, 1967; Zeff, 1971) pretending that these countries share approximate development patterns (e.g., Nobes, 1984) or based on the international classification and the nature of accounting practices. The country grouping might also be the result of an analysis of the accounting practices linked to several economic, political, social and cultural factors (Zhang et.al, 2019).

According to Gray (1988), conservatism varies according to country, ranging from a strongly conservative approach in the Continental European countries, such as France and Germany, to the much less conservative approach in the USA and UK. Indeed, the analysis that is determined according to the Hofstede-Gray prepositions and classifications needs to be empirically tested in order to prove their reliability in the Near Eastern cultural-accounting area. 


\subsection{Research design and methodology}

Several measures have been undertaken to maintain the validity and the reliability of the survey. Indeed, the research instrument is adapted from Doupnick and Riccio (2006) with certain adaptations to the current research context. The original study was undertaken in different cultural areas (i.e., Brazil and the UK), and obtained relevant results confirming the validity of the research instrument in studying the cultural effect on certain aspects of accounting judgments. Moreover, a pilot test was performed before administrating the questionnaire to the target samples. In the first place, the research instrument was distributed to a minor sample of 20 Ph.D. accounting students in a Tunisian university (IHEC Carthage) during their doctoral course. The comments received helped to improve the quality of the requirements before reaching the main samples.

Basically, this study relies on the responses of postgraduate accounting students in Tunisia and Egypt. For the Tunisian sample, the questionnaire was administrated by hand to postgraduate accounting students enrolled in a Ph.D. or a Masters' program in the leading public universities in business studies (e.g., IHEC Carthage, ISCAE Manouba, FSEG Tunis and FSEG Sfax). The research instrument was distributed to the participants during an accounting course session, the main tasks related to the IFRS excerpts interpretation were explained, and finally the completed questionnaires were directly collected. The same approach was followed by Oussi and Klibi (2017) in the Tunisian higher education context to gather data from students enrolled in three business schools in order to give insight into the improvement of communication skills, which is crucial for the development of a successful accounting career.

Regarding the Egyptian sample, and due to the accessibility constraint, the online version of the questionnaire was administrated via Google-forms and Qualtric-Surveys applications to postgraduate accounting students in Egyptian public business universities (e.g., Ain Chams University, Cairo University and Alexandria University). In order to maintain the reliability of the answers, we verified that all the targeted universities in both countries offer a course of IAS/IFRS in the Masters' program. Besides, the participants of the survey were asked to confirm that they have received this type of accounting course before answering the questionnaire. This step was judged important for the accurate understanding of the required tasks and to ensure the relevance of the answers. Moreover, the accounting decision making based on the IFRS extracts 
was based on attributing numerical values to the uncertainty expressions used as thresholds for recognition and disclosure decisions. This protocol follows previous research undertaken in the same context of IFRS interpretation. For instance, Zhang et al. (2019) propose this verbalnumerical strategy as a solution to reduce the potential impacts of uncertainty expressions on accounting judgments and to improve the communication of accounting information.

The data collection process was accomplished in three months, and this time period was sufficient to reach a number of responses that are adequate for the statistical data analysis and so it would be comparable to previous studies (e.g., Tsakumis, 2007 and Kolesnik et al., 2019).

This study extends previous research from a comparison between the Anglo and Germanic countries (e.g., Tsakumis, 2007) or the Anglo and Asian countries (e.g., Chand et al., 2009) to a part of the world where little attention so far has been paid: The North African countries/Arab countries. As illustrated in figure 2, the more current classification of the Arab countries' cluster according to Hofstede's model includes twelve countries (i.e., Morocco, Bahrain, Libya, Lebanon, Jordan, UAE, Egypt, Oman, Iraq, Kuwait, Saudi Arabia and Syria). This cluster is not exhaustive enough to cover all the Arab countries (i.e., for example Tunisia, Algeria, Yemen, Qatar and Sudan are the missing Arab countries), even though it was updated through the different versions of Hofstede's researches (1980, 1994, 2013). Moreover, Hofstede's framework does not include certain countries in his country classification according to their specific cultural indexes/scores (e.g., Tunisia, Bolivia) as reported by McSweeney (2002). Despite the fact that every edition of the Hofstede's Value Survey Module is an enhancement of the previous one that encompasses the perceived flaws, various countries are still neglected in the culture classification model. Hence, this study aims at determining Tunisia's cultural values' scores and to update those related to Egypt, as determined in 2010, and to study the extent to which a potential consistency exists among the Arab world. Moreover, the effect of these cultural values, imbued in Gray's (1988) accounting values of conservatism and secrecy, on the accounting judgments would be considered in Tunisia and Egypt. This cultural-accounting investigation represents, to the best of our knowledge, an area of research that has not been previously explored in similar studies.

Besides, the choice of these particular countries is based on the fact that previous studies undertaken in this particular cultural context (Arab region) have relied on the Arab countries' 
cultural indexes in order to understand and explain the accounting/management behavior based on the cultural attributes of the samples. The cultural values on which the analysis is based, are those related to the Arab world, in general, and defined by Hofstede (1980, 2010) (e.g., Seror and Rejeb, 1996; Ben Mrad and Boussaada, 2008; Dakhli, 2009). Nevertheless, it would be more accurate to determine updated culture scores for the specific sample and the country studied in order to base the analysis and the interpretation of the findings on more actual and precise cultural dimensions' indexes. This approach follows previous research such as Tsakumis (2009) for Greece and the US, and Doupnick and Riccio (2006) for Brazil and the US. Besides, this study chose Tunisia and Egypt representing the Arab region, as part of the North African area, in order to investigate the consistency of the cultural characteristics of countries belonging to the same culture context and their potential impact on the accounting judgments, which was partly verified earlier by Askary et al. (2008) who confirmed that the accounting practices in Arab countries $^{5}$ are supported by the uniformity and consistency of their cultural values. This study would further corroborate the consistency of the cultural values in this part of the world or would indicate the existence of a sub-culture within the Arab world expressed in terms of specific and different cultural values for each or both countries.

Our sample selection criteria follow previous studies undertaken in the accounting discipline and which rely on the responses of accounting students to test their hypotheses. For instance, Du \& Stevens (2016) focus on final year under-graduate accounting students' interpretation of the IAS/IFRS and Chand et al. (2012) also investigate the effect of national culture and education on the judgments of Australian and Chinese final year undergraduate accounting students in Australia based on the same standards' appraisal. Moreover, Salleh et al. (2011) compare native Chinese speaking and native English-speaking accounting students in United Kingdom universities and found that native culture and language are not important factors in the explanation of differences between accounting students in their interpretation of verbal probability expressions (VPE). However, a more recent study by Tang \& Yang (2016) reports a high degree of consistency in the VPE interpretations among Chinese auditors, while students' interpretations tend to exhibit lower levels of consensus.

\footnotetext{
${ }^{5}$ Askary et al. (2008) used a combination of survey and analysis of 132 listed companies' (excluding banks and financial institutions) annual reports and other published data in six countries namely, Bahrain, Jordan, Kuwait, Oman, Qatar and Saudi Arabia to study the accounting uniformity and consistency in the Arab nations.
} 
Moreover, our use of the latest available version of the VSM (2013) for determining the cultural scores for Tunisia and Egypt follows the same pattern as the extension of the IBM model by $M$. Bond in China called the Chinese Value Survey (CVS) based on students' responses and revealing four values that are fairly similar to Hofstede's original dimensions. Besides, the choice of these particular sample criteria is basically related to the preliminary stage of the IFRS convergence process in Tunisia and Egypt. Actually, both countries' accounting systems are largely based on the international accounting standards ${ }^{6}$, however the full convergence to this accounting framework needs more work on the financial, educational and technical backgrounds and seems to be a long-term project. In fact, professionals as well as companies need to be well prepared for this step to properly apply the international accounting framework (Ward and Lowe, 2017).

Moreover, the choice of accounting students as the respondents to our survey is performed to test their ability to properly understand and interpret the international accounting standards before they effectively apply them as professional accountants. We then attribute a great importance to the appropriate accounting education as a performance indicator of the Arab students' efficiency, as compared to international students to compete professionally, later, at the international level, especially with the increase of the staff displacement flow across countries. In addition, previous studies testing the attitude towards different aspects of the accounting/auditing disciplines have relied on samples of accounting students as substitutes for professional accountants, and empirical evidence proves that students can be an adequate replacement for practitioners in decision-making assignments (Gregory and Markus, 2005). Actually, the ultimate advantage of students as surrogates might be their greater accessibility and the cost-effectiveness as compared to practitioners (Waldron and Fisher, 2017). For instance, Ahlawat and Nouri (2015) examine the perception of auditors and non-auditors in the case of reporting a misstatement by comparing between non-business students (as proxies for general public) and senior accounting students' (as proxies for accounting professionals) sensitivity towards auditors that are not reporting a material misstatement in the financial statements. In particular, studies that have investigated the ethical behavior of professional accountants in several ambiguous situations have used accounting

${ }^{6}$ The Tunisian accounting system of 1997 and the Egyptian accounting systems of 1996 and 2006 are mainly inspired by the IASB accounting standards. Many Tunisian accounting standards are a pure reproduction of certain IAS/IFRSs (e.g., NCT 35 is a reproduction of IAS 27). 
students as proxies to measure the truthfulness of financial reporting. This was also followed by Chandra et al. (2016) and Waldron and Fisher (2017). This was also the case for Belkaoui (1980), Houghton and Hronsky (1993) who used accounting students as surrogates for accountants and proved the suitability of their use in the study of the connotative meaning of accounting. While Ashton and Kramer (1980) used them as proxies for auditors in a decisionmaking context that is a replication of Ashton's (1973) experiment looking at the internal control judgments carried out by internal auditors. The authors claim that students are reasonable surrogates for the real world providing a direct interest for the researchers and they provide additional evidence on their adequacy as surrogates in accounting research as it was the case of Murphy and Yetmar (2015) and (Lyanararchchi, 2007). Moreover, in Mortensen et al.`s (2012) study, the circumstances in which the use of students as surrogates for accountants was found to be relevant in accounting research. They found that advanced level accounting students (Masters/Ph.D) represent appropriate proxies for accounting practitioners in structured decision contexts. In fact, these candidates have certain professional experience as trainees or part/full time employees as in accounting firms which make them suitable for such an experiment. Moreover, students at this level are supposed to complete the most advanced level financial accounting courses, which is consistent with the literature claiming that the ability to make a judgment based on accounting standards is an important feature of audit assessment (Bedard, 1991), which is gained through proper accounting education acquired by upper-division and graduate accounting students supported in structured accounting contexts (Mortensen et al., 2012). Therefore, based on the previous literature that are using accounting students as surrogates for practicing accountants in decision-making contexts based on accounting standards, this study relies on the responses of post-graduate accounting students in Tunisian and Egyptian universities.

In order to preserve the relevance of our comparison between the two selected countries, our samples comprise around 200 postgraduate accounting students respectively in Tunisia and Egypt. The choice of this number of questionnaires distributed is based on previous studies discussing the same issue such as Doupnik and Riccio (2006) for their Brazilian and US samples, and Doupnik and Richter (2003) for their US and German samples. 
It is argued that there are two factors that affect the choice of the research method: the nature of the investigation and the type and availability of the data (Annasser, 2017). Basically, this study aims at examining the effect of the conservatism and secrecy values on the interpretation of the IAS/IFRS by Tunisian and Egyptian accounting students. Therefore, the study is performed at the individual level, contrary to the country level, where the analysis of the annual reports is the source of information used to understand the accounting system development. This study combines two parts of the analysis: to compute for Hofstede's cultural scores for Tunisia, which are not available in previous studies, and to actualize those related to the Egyptian sample, as well as the decision-making task based on different IAS extracts. Therefore, a primary source of data is necessary to test the study's hypotheses to enable the respondents to answer the Hofstede questionnaire (i.e., to compute for the culture score) and to assign a percentage to the probability expressions (PE) included in each IAS extract. The research instrument used in this study is a survey questionnaire including three major parts: part 1 is devoted to the demographic questions in order to gather information about the sample characteristics (i.e., age, gender, nationality at birth, experience) whereas part 2 is dedicated to the Hofstede culture-questionnaire (VSM, 2013) employed to account for the updated culture scores for our samples. Lastly, part 3 includes the decision-making questionnaire based on 13 IFRS excerpts including the PE.

\subsection{Variables}

The independent variable in this study is culture with two levels: Tunisia and Egypt. To test the first conservatism hypothesis $\mathrm{H} 1$, six dependent variables are used as the threshold to recognize the increase in net income. The participants are asked to assign the numerical probability ranging from 0 to $100 \%$ to each of the PE used to recognize an increase in net income (i.e., probable, reasonable assurance and reasonable certainty) included in six IFRS (i.e., IAS18, IAS20, IAS11, IAS12, IAS17 and IAS38). For instance, the participants are asked to assign a percentage that estimates the probability expression 'reasonable assurance' used in IAS 20, 'Accounting for

Government Grant and disclosure of Government assistance', as a threshold to recognize a revenue related to the recognition of the obtained Grant: "A Government grant is recognized when there is reasonable assurance that: (b) the grant will be received". The sample with a higher level of conservatism is supposed to assign a higher mean probability to the PE included 
in the IAS related to items that increase net income than the sample with a lower level of conservatism, in order to defer their recognition. In fact, according to Gray (1988), a country with a high level of conservatism is characterized by a cautious approach to measurement and recognition decisions, as opposed to a more risk-taking and optimistic approach. The same task is performed for the remaining five IFRS extracts.

To test the second conservatism hypothesis $\mathrm{H} 2$, four dependent variables are used as thresholds to recognize a decrease in net income. The participants are asked to assign a numerical probability ranging from 0 to $100 \%$ to each of the PE (i.e., probable, virtually certain and more likely) included in the four IAS extracts (i.e., IAS11, IAS12, IAS37, IAS38). For instance, the participants are asked to allocate a percentage that estimates the probability expression probable used in IAS11," construction contract", as a threshold to recognize an income decreasing item (i.e., IAS 11 requires a recognition of a loss on construction contracts when the loss is probable). The sample with a higher level of conservatism is expected to assign a lower mean probability to the PE included in the IAS related to items that decrease net income than the sample with a lower level of conservatism in order to accelerate their recognition. The same task is repeated for the other three PE.

To test the secrecy hypothesis $\mathrm{H} 3$, two dependent variables are used as a threshold for disclosure. The participants are asked to assign a numerical probability ranging from 0 to $100 \%$ to each of the two PE (i.e., probable and remote) included in two extracts from IAS37: Provisions, contingent Assets and contingent liabilities. The sample with a higher level of secrecy is expected to assign a higher mean probability to the PE related to items associated with disclosure than the sample with a lower level of secrecy, in order to defer or avoid the disclosure of both contingent assets and contingent liabilities. In fact, a country with a high level of secrecy tends to have restricted disclosure behavior and avoid the broad disclosure of information about the business in the financial statements. This confirms a restricted disclosure tendency that implies a secretive approach in the financial reporting as opposed to a more open and transparent approach. Table 2 outlines the research variables tested according to the different hypotheses. 
Table 2. The research variables

\begin{tabular}{|c|c|c|c|}
\hline Accounting value & \multicolumn{2}{|l|}{ Conservatism } & Secrecy \\
\hline Hypothesis & $\begin{array}{l}\mathrm{H} 1 \text { : recognition of increase } \\
\text { in income }\end{array}$ & $\begin{array}{l}\mathrm{H} 2 \text { : recognition of decrease in } \\
\text { income }\end{array}$ & H3: Disclosure \\
\hline $\begin{array}{l}\text { Independent } \\
\text { variable }\end{array}$ & \multicolumn{3}{|l|}{ Culture: Tunisia vs. Egypt } \\
\hline $\begin{array}{l}\text { Dependent } \\
\text { variables: IAS }\end{array}$ & $18,20,11,12,17,38$ & $11,12,37 \mathrm{a}, 37 \mathrm{~b}, 38$ & $37 \mathrm{c}, 37 \mathrm{~d}$ \\
\hline $\mathbf{P E}$ & $\begin{array}{ll}\text { Probable, } & \text { reasonable } \\
\text { assurance, } & \text { reasonable } \\
\text { certainty } & \end{array}$ & $\begin{array}{l}\text { Probable, virtually certain, } \\
\text { more likely }\end{array}$ & Probable, remote \\
\hline Decision making & $\begin{array}{l}\text { Recognize increase in net } \\
\text { income }\end{array}$ & $\begin{array}{l}\text { Recognize decrease in net } \\
\text { income }\end{array}$ & $\begin{array}{l}\text { Disclose contingent assets } \\
\text { and contingent liabilities }\end{array}$ \\
\hline
\end{tabular}

\section{Findings and discussion}

\subsection{Demographic results}

Table 3 summarizes the demographic results for the Tunisian and the Egyptian samples. Out of the 200 questionnaires distributed to each group, 72 have been collected from the Tunisian sample and 90 from the Egyptian sample with respective response rates of $36 \%$ and $45 \%$. These responses are comparable to prior research that is collecting data from participants based on the Hofstede VSM in order to determine the updated culture scores. For instance, Tsakumis (2007) who examines the effect of conservatism and secrecy on accountants' professional judgment, got a response rate of $38.5 \%$ for the Greek sample and 53\% for the American sample. Simon (2002), considered as the first study that is looking at the consistency in the interpretation of the probability expressions in the IFRS in the Anglo area, reached a response rate of $24.7 \%$ based on 74 returned questionnaires with over 300 sent to UK auditors. In the Portuguese culture area, Teixeira and Fialho (2009) got a higher response rate (78\%) which might be due to the low number of questionnaires emailed to the Portuguese auditors compared with the studies mentioned above (i.e., 35 received over 45 emailed). Doupnik and Riccio (2006) also obtained close response rates for their Brazilian and American samples reaching $38.5 \%$ and $53.5 \%$ respectively. 
Table 3. Demographic Results

\begin{tabular}{|c|c|c|c|}
\hline & Tunisia & \multicolumn{2}{|l|}{ Egypt } \\
\hline Questionnaires distributed & 200 & \multicolumn{2}{|l|}{200} \\
\hline Number of responses & 72 & \multicolumn{2}{|l|}{90} \\
\hline Males & $32(44,4 \%)$ & \multicolumn{2}{|c|}{$56(62.2 \%)$} \\
\hline Females & $40(55.6 \%)$ & \multicolumn{2}{|c|}{$34(37.8 \%)$} \\
\hline Mean age & 25.3 & \multicolumn{2}{|l|}{24.7} \\
\hline Professional Master & \multirow[b]{2}{*}{$52(76 . \%) \quad 23$} & & 17 \\
\hline students $\quad$ Master of Research & & & $58(63 \%)$ \\
\hline PhD students & 20 & \multicolumn{2}{|l|}{32} \\
\hline Response rate & $36 \%$ & \multicolumn{2}{|l|}{$45 \%$} \\
\hline
\end{tabular}

This study's responses indicate a higher presence of the female respondents in the Tunisian sample (i.e., 55.6\% females vs. $44.4 \%$ males) than in the Egyptian sample (i.e., $37.8 \%$ females vs. $62.2 \%$ males). Based on the last updated and available statistics related to the Tunisian universities, the percentage of the registered females in the $\mathrm{PhD}$ studies is $67 \%$ in 2015 while those registered in the Professional Master program is 52.6\%, while in the Master of research it is $70.9 \%$ (Office of planning and programming studies, 2016), which explains the higher number of females respondents to our survey. For the Egyptian side, the UNESCO (2016) statistics about the tertiary education in Egypt show an approximate gross enrolment rate between male and female (i.e., $34.04 \%$ and $34.85 \%$, respectively). The mean age of the postgraduate students involved in this research is very approximate for both samples (i.e., 25.3 for Tunisia and 24.7 for Egypt). For both groups, the majority of the participants are masters' students (i.e., 76\% for Tunisia and 63\% for Egypt), since the number of the registered students in the Masters' degrees in the accounting curriculum is higher than the number of $\mathrm{PhD}$ students, according to the statistics revealed by the Ministry of higher education. 


\subsection{Culture scores}

Since the original culture scores for the Arab countries have been determined by Hofstede more than 3 decades ago (1980), and those for Egypt have been determined separately in Hofstede's book 'Cultures and Organizations' published in 2010, this study aims at re-determining the alternative scores for both countries (based on the study's samples) by administrating the last updated version of Hofstede's value survey module (VSM 2013) questionnaire to post-graduate accounting students in both countries. For instance, as At-Twaijri et al. (1996), which is based on a research undertaken in the GCC countries, assume that the cultural dimensions in any nation may change. This was confirmed by Fernandez et al. (1997) who investigate the reliability of the Hofstede country classification 25 years later based on data gathered from 9 countries proving the occurrence of many changes, mainly based on environmental factors. With regards to this study's specific culture context, Ben Rejeb (2016) assumes that even Tunisia and Egypt are always classified into the same cultural cluster, and that they still have different cultural characteristics. Thus, this study`s re-examination of this country classification may confirm the direction of the proposed hypotheses and validate the country grouping that could be altered due to geographical, social, economical and political transformations, and it also confirms whether Tunisia's scores fit into the Arab countries' categorization as it is for Egypt or not. Indeed, due to the lack of identification of Tunisia in Hofstede's model (see figure 2), this has always risen the need for researchers that are working on the Tunisian cultural/management-accounting context to attribute the Arab countries' scores to Tunisia in order to be able to analyze the effect of the cultural characteristics on different aspects of business management (e.g., El Akermi et.al, 2007; Dakhli, 2009). It is then, more accurate to verify Tunisia's cultural values' scores that may or may not fit the Arab culture context, which is not a homogeneous concept (El Louadi, 2004).

Indeed, cultural dimensions are only an important step leading to understand the profound density of the Tunisian culture (Venkateswaran and Ojha, 2019). Following previous replications of Hofstede's model performed in different Arab countries, either to make an update of the cultural scores (Akhlaffou, 2020, Morocco; Fischer and Al-Issa, 2012, for six Arab countries; Alkailani et al., 2012, Jordan) or to claim certain cultural specificities (Mansour et al., 2019, Sudan and Al-Nashmi and Zin, 2011, Yemen). 
The score estimate is based on the formulas constructed by Hofstede (2013) and included as a part of the VSM-2013 manual available at Geert Hofstede's website in different languages, and which is freely used for research purposes. ${ }^{7}$

The formulas used to determine each culture dimension score are expressed as follows:

*Power Distance-PD index $=35(\mathrm{~m} 07-\mathrm{m02})+25(\mathrm{~m} 20-\mathrm{m} 23)+\mathrm{C}(\mathrm{pd})$

Where $\mathrm{m} 07, \mathrm{~m} 02, \mathrm{~m} 20$ and $\mathrm{m} 23$ are the mean response for question 2 , etc..., and $\mathrm{C} \mathrm{a}$ constant that depends on the nature of the sample. Similarly, the formulas for the other four dimensions are stated as follows:

*Individualism- Collectivism- IDV-COLL index $=35(\mathrm{~m} 04-\mathrm{m} 01)+35(\mathrm{~m} 09-\mathrm{m} 06)+\mathrm{C}($ ind $)$

* Masculinity- Femininity-MAS-FEM index $=35(\mathrm{~m} 05-\mathrm{m} 03)+35(\mathrm{~m} 08-\mathrm{m} 10)+\mathrm{C}(\mathrm{mf})$

* Uncertainty avoidance-UA index $=40(\mathrm{~m} 18-\mathrm{m} 15)+25(\mathrm{~m} 21-\mathrm{m} 24)+\mathrm{C}(\mathrm{ua})$

* Long-term Orientation-LTO index $=40(\mathrm{~m} 13-\mathrm{m} 14)+25(\mathrm{~m} 19-\mathrm{m} 22)+\mathrm{C}($ lto $)$

Table 4 presents the index scores for Tunisia and Egypt as reported by Hofstede (1980, 2010). The direction of the difference between each value-score is presented in order to be compared later-on with the scores determined in this study.

Table 4. Hofstede's inde scores for Tunisia (the Arab world) and Egypt

\begin{tabular}{lrrr}
\hline Cultural value & Tunisia & & Egypt \\
Power distance & 80 & $>$ & 70 \\
Collectivism & 46 & $>$ & 25 \\
Masculinity & 53 & $>$ & 45 \\
Uncertainty avoidance & 68 & $>$ & 80 \\
Long term orientation & 26 & $>$ & 7 \\
Indulgence & 32 & & 4 \\
\hline
\end{tabular}

${ }^{7}$ http://geert-hofstede.com 
According to Hofstede (2013), the culture index scores usually range from 0 to 100 . The sample that ranges lower than the mean (50) in a particular culture is supposed to have a low level of that cultural dimension and the sample that ranges higher than 50 is supposed to have a high level of that cultural dimension. Based on this arrangement on Hofstede's original scores, Tunisia and Egypt are characterized by high power distance indexes (80 and 70), which tend to be masculine societies (i.e., the 53 and 45 indexes are close to the average masculinity score of 50) with differentiated gender roles (Latiri \& Smida, 2004). Meanwhile, Egypt seems to have more collectivist social trends than Tunisia with a lower score of 25 vs.46. Both countries share a high degree of uncertainty avoidance (68 and 80) as demonstrated by Ben Rejeb et al. (2003) with a tendency to short-term orientation (26 and 7) while being more restrained than indulgent (32 and 4). For a more updated presentation of the cultural identity of this study's sample, table 5 outlines the cultural value scores determined for the samples of postgraduate accounting students in Tunisia and Egypt.

\section{Table 5. Alternative cultural scores for Tunisia and Egypt determined in this study}

\begin{tabular}{lllll}
\hline Cultural value & Tunisia & & Egypt & $\begin{array}{l}\text { Direction of difference consistent } \\
\text { with Hofstede's scores }\end{array}$ \\
Power distance & 30 & $<$ & 32 & No \\
Individualism/collectivism & 40 & $>$ & 20 & Yes \\
Masculinity/femininity & 27 & $>$ & 15 & Yes \\
Uncertainty avoidance & 10 & $<$ & 50 & Yes \\
Long/short term orientation & 34 & $>$ & 10 & Yes \\
Indulgence/Restraint & 41 & $>$ & 22 & Yes \\
\hline
\end{tabular}

Based on the VSM 2013, the results of the alternative scores determined for the sample of postgraduate accounting students in Tunisia and Egypt reveal a considerable shift in terms of the values of each of the cultural dimensions as compared to the original scores determined by Hofstede for the Arab countries and Egypt (i.e., these scores range from 0 as the least value and 100 as the highest value for each dimension, whereas a value of 50 corresponds to a moderate 
rank $)^{8}$. However, the difference between the two countries is in the same direction as the Hofstede (2010) scores for five out of six cultural dimensions as appears in table 4. It is worth mentioning that the results for Tsakumis (2009), which show updated scores for Greece and the US, are also in the same direction for 4 out of 5 of the studied cultural values (i.e., the difference is obtained for the Masculinity dimension). Tsakumis (2009) argues that since the cultural scores are only determined at the country level, and not at the individual level, it is not possible to assess the statistical significance of the scores' differences which led him to conclude that his updated scores are consistent with Hofstede's original scores. Patel et al. (2002) and Patel (2003) are also two accounting studies which incorporate Hofstede's VSM into their research instruments in order to verify the cultural characteristics of the participants (i.e., Australian, Indian and Chinese Malaysian). It is important to state that these cultural scores may be valid for other organizational contexts; however, a rigorous re-evaluation for each context would be preferable to ensure that the scores are stable for every study, which relies on the effect of the cultural values on any accounting aspect. This study would represent a reference for comparison in the case of the same contextual circumstances. In fact, the previous replications of the Hofstede study are using his VSM as tool to determine cultural scores that focus on specific groups of respondents (e.g., Shane ,1995, government employees; Meritt, 1998), pilots; Van Nimwegen (2002), banks' employees) and are presenting results confirming three out of the four dimensions studied (i.e., the non-confirmed value is different for each study).

Based on the alternative cultural dimensions' scores obtained for Tunisia and Egypt, and in relation to Gray's conservatism and secrecy hypotheses, it is clear that the Egyptian sample would exhibit higher conservatism and secrecy than the Tunisian sample. In fact, The Egyptian sample ranks higher in terms of uncertainty avoidance and lower in terms of masculinity and individualism which suggests a more conservative approach to accounting recognition. Moreover, the Egyptian sample ranks higher than the Tunisian sample in terms of uncertainty avoidance and power distance, and lower in terms of masculinity and individualism which suggests a more secretive approach to accounting disclosure.

\footnotetext{
${ }^{8}$ Hofstede notifies that the administration of the current version of the VSM revised in 2013 will not necessarily result into similar scores to those obtained in his original study. However, he advises that the difference between two countries in terms of these scores should be the same.
} 


\subsection{Test of Hypotheses}

Table 6 summarizes the study's expectations related to whether the Egyptian or the Tunisian sample would assign a higher/lower mean probability expression to the probability expressions included in the research questionnaire, and which are assembled according to each of the three hypotheses. These expectations are based on the hypothesized relationship between the cultural values' level (high/low) and the level of accounting values of conservatism and secrecy as proposed by Gray (1980), and how these statuses affect the accounting decision making by being less/more conservative/secretive. According to these levels of the two accounting values as proposed in our three research hypotheses, we present our expectations of how they impact the accounting judgments related to the recognition or disclosure as performed by Doupnick and Riccio (2006) and Doupnick and Richter (2003). For example, IAS 20: 'Government Grant', stipulates that the revenue (grant) should be recognized 'when there is reasonable assurance that the entity will comply with the conditions attached to it, and the grant will be received' (para.7). In this context, the term reasonable assurance is used to establish the recognition of an item that increases net income. If the Egyptian participants are more conservative than their Tunisian counterpart and they prefer to defer the income recognition, they should assign a higher numerical probability (on a $0-100 \%$ scale). The responses to this extract of IAS20 are used to test the first conservatism hypothesis H1, and five more extracts of different IAS are used for that purpose (i.e., IAS18, IAS11, IAS12, IAS17, IAS38).

To test $\mathrm{H} 2$ related to the decrease in income, five IAS extracts including probability expressions are used. For example, IAS11: 'Construction contract' specifies that an expected loss on a construction contract 'should be recognized when it is probable that total contract costs will exceed total contract revenue' (para.36). In this context, the term probable is used to determine the recognition of an item that decreases net income. If the Egyptian participants are more conservative than their Tunisian counterparts, they will assign a lower numerical probability (on a $0-100 \%$ scale) to accelerate the recognition of the decrease in income (i.e., being more conservative). Four additional IAS extracts are used to test H2 (i.e., IAS12, IAS37, IAS38).

Regarding the probability expressions used to make disclosure decisions, and whether it is related to the recognition of an increase or a decrease in income, Egyptian students are expected 
to assign a higher numerical probability (on a $0-100 \%$ scale) than the Tunisian sample to the items related to disclosure in order to avoid or defer the disclosure of information about the company (i.e., being more secretive). The participants' decisions based on two different extracts from IAS37: 'Provisions, contingent assets and contingent liabilities' are used to test the secrecy hypothesis $\mathrm{H} 3$ since it includes items related to the disclosure of contingent assets and contingent liabilities incorporating probability expressions. The Egyptian students, being more secretive, are expected to assign higher numerical probability to items related to the disclosure of information related to contingent assets and contingent liability than the Tunisian students who are expected to exhibit a lower level of secrecy. This judgment would allow the first group to delay the disclosure of this particular information in the notes to the financial statements.

Table 6. Expectations for differences in mean numerical probability between Tunisian (TUN) and Egyptian (EGY) postgraduate accounting students in the interpretation of PE.

\begin{tabular}{|c|c|c|c|c|}
\hline IAS\# & $\mathrm{PE}$ & Context & Impact on income & Expectations \\
\hline \multicolumn{5}{|c|}{ H1: Recognition of increase in income } \\
\hline 18 & Probable & Revenue & + & EGY>TUN \\
\hline 20 & Reasonable assurance & Government Grant & + & EGY>TUN \\
\hline 11 & Probable & Construction contract gain & + & EGY>TUN \\
\hline 12 & Probable & Deferred tax asset & + & EGY>TUN \\
\hline 17 & Reasonable certainty & Leases & + & EGY>TUN \\
\hline 38 & Probable & Intangible assets & + & EGY>TUN \\
\hline \multicolumn{5}{|c|}{ H2: Recognition of decrease in income } \\
\hline 11 & Probable & Construction contract loss & - & EGY<TUN \\
\hline 12 & No longer probable & Deferred tax asset & - & EGY<TUN \\
\hline 37 & Probable & Provision & _- & EGY<TUN \\
\hline 37 & More likely & Provision & - & EGY<TUN \\
\hline 38 & Virtually certain & Intangible asset & - & EGY<TUN \\
\hline \multicolumn{5}{|c|}{ H3: Disclosure } \\
\hline 37 & Remote & Contingent liability & none & EGY>TUN \\
\hline 37 & Probable & Contingent asset & None & EGY>TUN \\
\hline
\end{tabular}


Table 7 reports the mean numerical probability assigned by the Tunisian and Egyptian postgraduate accounting students to the study's 13 VPE selected from nine different IAS/IFRS. The order in which the IAS extracts appear in the research questionnaire is random for each version (i.e., French and English). Based on the statistical tool SPSS-23, the multi-analysis of variance (MANOVA) test is used to examine whether there is a significant global difference between the Tunisian and Egyptian participants across each set of PE related to each of the three hypotheses. Later on, the responses to individual PE are examined based on a series of ANOVA, in order to find out whether the direction of the difference is consistent with the hypothesis, and which of the selected PE contribute to this difference between the two samples. In fact, ANOVA or the analysis of variance is a group of statistical models used to test the significant difference between means and allows the researchers to conclude whether the means of different groups are equal or not (Research optimus.com).

Regarding the first conservatism hypothesis (H1), table 7 illustrates the MANOVA statistical test indicating a significant difference $(p=0.000)$ between the two groups of accounting students in Tunisia and Egypt across the six probability expressions (PE) related to the recognition in increase in income. The $F$ value or significance value indicates whether the variance between the means of two populations is significant. Thus, the $F$ value indicates the $p$ value; that is where the $p$ value is the probability of getting a result at least as extreme as what was actually observed. The $F$ ratio is a statistical test calculated as the variance of the group means or the mean of the within group variances. This value designates whether there is more variation between the two groups instead of within the groups. Regarding the homogeneity test, it is not valid to run it for our samples since the sample sizes are close to each other (i.e., N=72 for Tunisia and N=90 for Egypt). 
Table 7. Mean numerical probability assigned by Tunisian and Egyptian postgraduate accounting students and results of statistical tests

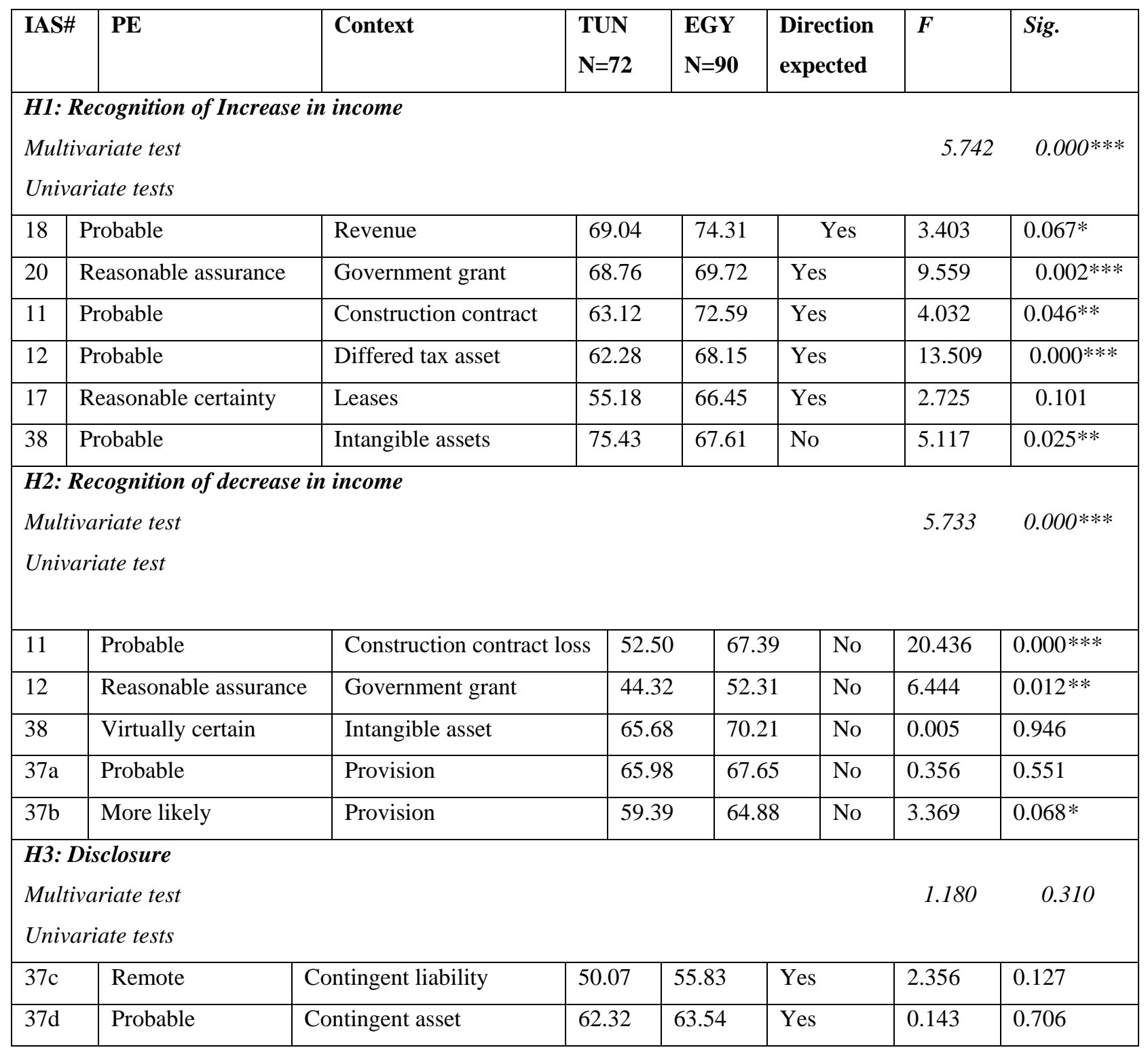

With regards to the mean numerical probability assigned by the two groups to each of the six PE, the results show that the difference in the mean probability occurs in the predicted direction (see table 6) in five out of the six probability expressions (i.e., probable, reasonable assurance and reasonable certainty). Moreover, in four out of the five results that occur in the predicted direction, the mean difference between the two groups is significant with regards to the term 
probable in IAS18 (74.31 vs.69.04), probable in IAS11(72.59 vs. 63.12), probable in IAS12 (68.15 vs. 62.28) and reasonable certainty in IAS17 ( 66.45 vs. 55.18).

This means that the Egyptian postgraduate accounting students assign higher numerical probability (on a $0-100 \%$ scale) to the stated PE related to the increase in net income than their Tunisian counterparts. Thus, the first group (Egyptian) demonstrates a tendency to delay the recognition of the items that would positively affect the net income, showing a more cautious approach in financial reporting than the second group (Tunisian) being more conservative.

This result confirms Guemazi and Halioui`s (2019) study pertaining that accounting judgements made in more uncertainty avoiding countries (Egypt) tend to be more conservative. This is also evidenced by Haller and Wehrfritz (2014) testing the conservative approach of British and German accountants when they express recognition judgments under the IFRS.

The ANOVA results (univariate tests) designate significant differences $(p<0.05)$ between the two samples of respondents in four out of the six cases (i.e., reasonable assurance in IAS20, probable in IAS11, IAS12 and IAS38). Only one difference in terms of the recognition of increase in income is in the opposite direction (i.e., probable in IAS 38: Recognition of intangible assets) for which this difference is significant $(p=0.025)$. Consequently, culture, through its effect on the accounting value of conservatism, influences the interpretation of the probability expressions related to the recognition of the increase in income. These findings corroborate with Kolesnik et al. (2019) who found evidence of a substantial difference in the manner that the Polish and the British interpret VPE cultural influences on their accounting judgements. The authors indicate that the Polish accountants tend to be more attached to the prudence principle than the British accountants which reflect their conservative way of the IFRS interpretation.

With regards to the second conservatism hypothesis (H2), the MANOVA statistical test indicates a significant global difference between the two groups of respondents in terms of the five probability expression used to test the decrease in income $(p=0.000)$ Meanwhile, the univariate tests (ANOVA) analyzing the differences in the mean probability assigned to each of the VPE related to the items that decrease net income happen in the predicted direction (i.e., probability assigned by the Tunisian participants is higher than the probability assigned by the Egyptian participants) in only one out of the five selected IASs (i.e., for the expression virtually certain 
included in IAS 38: Intangible assets), and for which the ANOVA does not indicate a significant difference $(p=0.946)$. Meanwhile, the ANOVA result shows a significant difference in three cases (i.e., Probable in IAS11, reasonable assurance in IAS12 and more likely in IAS37). However the significant difference does not happen in the expected direction where the Egyptian participants assign higher probability to the items related to the decrease in income than the Tunisian participants (more conservative) which would accelerate their recognition in the financial statement as a reaction to their uncertain nature by applying the concept of prudence? Therefore, for the second conservatism hypothesis $\mathrm{H} 2$, related to the decrease in income, it appears that culture, through its influence on the accounting value of conservatism, does not seem to affect the interpretation of the probability expressions related to the decrease in income. This result matches Doupnick and Riccio`s (2006) findings related to the difference in the mean probability assigned by Brazilian and US accountants to items related to the recognition of a decrease in income where in the opposite direction (i.e., probable in IAS 11, no longer probable in IAS12 and probable in IAS37). none of these differences are significant.

Regarding the secrecy hypothesis $\mathrm{H} 3$, testing the interpretation of the probability expressions related to items of disclosure of information in the notes to the financial statements (IAS37), the MANOVA statistical test indicates a non-significant global difference between the two groups of respondents $(p=0.310)$ with regards to the items related to the disclosure of contingent liability and contingent assets included in IAS37: Provisions, contingent assets and contingent liability. Moreover, the ANOVA results for the single probability expressions does not indicate a significant statistical difference for the mean probability assigned by the two samples to the terms remote $(p=1.27)$ and probable $(p=706)$ related to the disclosure of contingent assets and contingent liability. However, this difference occurs in the expected direction for both VPE related to H3 (i.e., the Egyptian sample assigns a higher mean probability than the Tunisian sample). This is consistent with the expectation that the Egyptian participants are less willing to provide accounting disclosure confirming their higher level of secrecy as compared to the Tunisian sample. Therefore, culture, through its influence on the accounting value of secrecy, influences the interpretation of the probability expressions related to the disclosure of

${ }^{9}$ Certain accounting transactions are uncertain and need to be reported in time in order to be relevant. Certain estimates that require judgments are performed in order to encounter this uncertainty. These judgments are made with caution and prudence which is a key accounting concept which ensures that assets and income are not overstated and liabilities and expenses are not understated (Jan, 2013). 
information in the Tunisian and Egyptian contexts. These results are approved by Naghshbandi et al. (2016) by claiming that culture is likely to influence the level of information disclosed, through the accounting value of secrecy, on the IFRS interpretations. However, this is not confirmed by (Haller and Wehrfritz, 2014) who did not find any significant difference between the British and German accountants' disclosure decisions on contingent assets, which implies a quiet similar secrecy dimension for both countries.

\section{Research implications and limitations}

This study empirically tested the Hofstede-Gray cultural accounting framework at the individual level in Tunisia and Egypt. It investigated the extent to which culture, through the accounting values of conservatism and secrecy, influences the Tunisian and Egyptian accounting students' interpretation of the probability expressions (PE) extensively used in the IAS/IFRS. More precisely, it assesses the cultural effect on the recognition of the increase in income, decrease in income and disclosure of this accounting information.

The results provide evidence of the generalizability of Gray's conservatism hypothesis in the North African/Arab countries (i.e., Tunisia and Egypt), at least in the context of income recognition. Moreover, the findings demonstrate that culture, through its influence on the accounting value of secrecy, affects the interpretation of PE used in the IFRSs to establish disclosures.

This study entails several theoretical contributions. Firstly, it determines actualized culture indexes of the Hofstede cultural values for Tunisia, which is missing in the Hofstede (19802010) Arab countries' grouping, and Egypt, for which the last published scores are only available since 2010 (i.e., in Geert Hofstede's book: Culture and Organizations. This particular assessment was undertaken in various previous studies examining the influence of culture on accounting practice such as Tsakumis (2007, 2009) and Doupnik and Richter (2006). This theoretical confirmation is important in order to make sure that the direction of the difference between the studied countries is still consistent with that initially proposed by Hofstede (1980) in order to accurately build the comparison between the studied countries in the context of Gray's accounting values of conservatism and secrecy. 
Moreover, various studies examining the effect of the cultural factors on various aspects of the accounting/management discipline refer to the Arab countries' global cultural indexes which are claimed to be general and do not depict the specificities of each Arab country, and which might present different cultural features from the others that belong to the same group (e.g., Seror and Rejeb.1996 and Ben Mrad and Boussaada, 2008).

Besides, this study investigates the impact of culture on the PE interpretation in the NorthAfrican/Arab culture area, and is testing Gray`s theory, especially the conservatism and secrecy hypotheses, at the individual level in Tunisia and Egypt.

This study has several practical implications, as well. For instance, it gives evidence on the variability in the IFRS interpretation in different countries, which engenders a difference in the application of the same accounting standard due to the national character influence. This certainly contradicts with the IASB's main objective of the international harmonization of accounting practices. Practically, this finding shall trigger the attention of the standard setters to reduce the frequency of these ambiguous expressions in the future issuance or revision of the IFRS, which may reduce the dissimilarities related to their interpretation. Consequently, it would improve the comparability of the financial statements at the international level and enhance their usefulness in the decision making.

Accordingly, the international financial interpretation committee (IFRIC) should come into play in this setting, as its main role is to provide useful comments about accounting issues that may give rise to unsatisfactory or contradictory interpretations. Thus, it should issue more interpretation standard that may reduce the ambiguity and the inconsistency in the interpretation of the IFRS including an extensive use of the probability expressions (e., as it is the case for IFRIC 23 clarifying the uncertainty over income tax treatment). The IASB, as the central organ guiding the convergence process, should put reasonable limits on the use of these terms in the international standards meant to be used in different cultural contexts (i.e., certain standards, such as IAS37, include four uncertainty expressions used as thresholds for recognition and disclosure requirements). 
These elements remain under the control of the IASB, and the IFRIC, as well as the national accounting bodies and the professional organizations in each jurisdiction formed to help ensure uniform interpretations (Alibhai and Johnstone, 2019). Hence, it seems substantial for the IASB as an international organization to take important preventive actions in order to reduce the variability of the future IFRS interpretations in different national settings. Hence, it may integrate members from different nationalities in the committee that is currently Anglo-culture dominated in order to endure the cultural potential influence in the standard setting process, taking into consideration the global harmonization objective that must encompass all the national differences that are able to deviate the accurate interpretation and application of the IFRS. For instance, members representing the Arab countries should attend the IASB, as the number of these jurisdictions converting to the IFRS is increasing over time (i.e., among the Arab counties applying the IFRS, we state the UAE, Saudi Arabia, Oman, Egypt, Jordan, Qatar, Iraq, Palestine, Kuwait, Syria, Yemen) which may engender a more stability in the financial reporting across this particular culture area, and hence improve the multicultural orientation of the IASB.

The study's policy implications engage a reconsideration of the use of PE with low communication efficiency, and the adoption of well-understood probability expressions with high communication efficiency, in order to enhance the appropriate understanding of the PE that would engender a better appraisal and interpretation of the whole standard.

As this study relies on the accounting students' interpretations of the IAS/IFRS, certain concerns were detected with regards to the communication efficiency of certain PE used in the international accounting standards, from both samples. For instance, there is the expression 'remote', which denotes a negative connotation and calls for a cautious recognition of the accounting elements (decrease in income). However, it has been attributed a percentage of realization higher than $50 \%$, which do not cope with the accurate accounting measurement requirement. This misunderstanding would affect the accurate interpretation and application of the accounting standards and calls for a more consideration from educators to place a stress upon the accurate interpretation of these recurrent uncertainty expressions in the related IFRS courses. This process would enhance the IFRS education in the developing countries which plan to converge towards the international standards as it is the case for Tunisia and Egypt (i.e., the 
IFRS will be applicable by the Tunisian local companies with public accountability and financial institutions counting from 2021, and are permitted for domestic companies in Egypt since 2017). Both countries adopt the IFRS education programs in their universities' accounting curricula as a crucial strategic approach to reasonably adapt the international accounting framework to the national settings. However, the educational approach needs further emphasis on the precise interpretation of the standards enclosing uncertain requirement elements. Basically, while using the IFRS as a tool for accounting judgement's measurement, this study recognizes the costbenefit complexity of IFRS adoption in emerging countries due to several contextual issues such as; corporate governance, fair value accounting and environmental distress (Shigufta, 2016). Moreover, education seems to be a decisive aspect enhancing the success of the IFRS adoption in any emerging country. As such, Yamani and Almasarwah (2019) identify the resistive factors of delaying the full IFRS adoption in Saudi Arabia including social, political, educational and religious perspectives.

Moreover, accounting educators need to pay greater attention to the interpretation of the PE in order to raise the awareness to the accounting students of these expressions and the uncertain contexts to which they are associated. In fact, the appropriate accounting education is a determinant for understanding accounting concepts and procedures (Belkaoui, 1983), and the preparation of a good accounting career. This was also suggested by Cable and Patel (2000) claiming that accounting educators need to pay greater attention to the role of various contextual factors in order to ensure that the relevance of the meanings intended in the official accounting pronouncements which are used as primary teaching materials are conveyed to students within specific cultural contexts.

As any research, this study presents certain limitations. Specifically, it relates to the sample selected among the accounting students in Tunisia and Egypt, which might not be representative of the Tunisian and Egyptian societies in terms of determining the actualized cultural indexes for both countries, and for the accounting decision making. Especially, the mean age for these samples is 25.3 and 24.7 years old for Tunisia and Egypt, respectively, which means that other age clusters and categories of citizens are not represented. This study drew samples from specific regions within Tunisia and Egypt. To the extent that there are regional differences with relation 
to cultural and accounting values, the results may not be generalizable to other regions. Future research may investigate this issue to cover different culture areas with different and larger samples to improve the generalizability of the results. 


\section{References}

Abbes, I., Mouelhi, N. B. D., \& Hallem, Y. (2017). L'orientation client des vendeurs comme moyen d'adaptation à l'international. Une étude comparative France-Tunisie sur le cas de l'enseigne Zara. Question ( $s$ ) de management, (3), 19-37.

Ahlawet,S. Nouri. H,(2015). An examination of accountants and non accountants` perceptions of auditors non reporting a material misstatement. Journal of business and accounting. 8 (1).p 51-63.

Akhlaffou, M. (2020). Culture nationale et pratiques manageriales au sein des organisations marocaines: une enquête empirique. Revue Economie, Gestion et Société, 1(22). 1-21

Alibhai, S., and Johnstone, C., (2019). Interpretation and application of IFRS standards. John Wiley and sons Ltd.

Alkailani, M., Azzam, I. A., \& Athamneh, A. B. (2012). Replicating Hofstede in Jordan: ungeneralized, reevaluating the Jordanian culture. International Business Research, 5(4), 71-80.

Al-Nashmi, M. M., Zin, S., \& Rahman, S. A. (2011). Variation in communication satisfaction of academic staff in universities in Yemen depending on national culture. Cross Cultural Management: An International Journal, 18(1), 87-105.

Askary, S. Pounder, J.S, \& Yazdif, H (2008). Influence of culture on accounting uniformity among Arabic nations. Education, Business and Society Contemporary Middle Eastern, 1(2), pp.145-154..

Belkaoui, A.R (1980). The Interprofessional Linguistic Communication of Accounting Concepts: An Experiment in Sociolinguistics. Journal of Accounting Research. Vol. 18, No. 2 .pp. 362-3741

Ben Ghodhbane, S (2013). IFRS and performance measurement. African Journal of Accounting, Auditing and Finance, Vol. 2, No. 2

Ben Rejeb, W., Berraies, S. (2016). Composition et rôles du conseil d'administration : quels effets sur l'innovation d'exploitation et l'innovation d'exploration? Cas des entreprises tunisiennes cotées. Conference of the international association of the strategic management.Tunisia

Ben Salem, R., Damak-Ayadi, S., Saihi, M. (2017). Determinants of Full IFRS

Adoption. International Journal of Managerial and Financial Accounting, 9(2): 105-123

Besbes, A., Legohérel, P., Kucukusta, D., \& Law, R. (2016). A cross-cultural validation of the tourism web acceptance model (T-WAM) in different cultural contexts. Journal of International Consumer Marketing, 28(3), 211-226.

Bouderbela,R., Eljammi,J.,Gherib,J. (2020). Relevance of Hofstede's model in identifing specific national cultural character: the case of a North Africain country. Social Business. Forthcoming 
Cable, D \& Patel, C (2000). Personality and Cultural Influences on Aggressive Financial Reporting Practices. Asian Review of Accounting. 8(2), pp. 60 - 80.

Chaminade, C \& Johanson, U (2003). Can guidelines for intellectual capital management and reporting be considered without addressing cultural differences? Journal of Intellectual Capital. 4(4), pp. $528-542$.

Chand, P, Cummings, L and Patel, C (2009). The effect of accounting education and national culture on accounting judgments. Paper presented at the 2009 accounting and Finance. Association of Australia and New Zealand (AFAANZ) annual conference Adelaide, Australia.

Chanchani, S \& Willet, R. (2004). An empirical assessment of Gray's accounting value constructs. The International Journal of Accounting. 14(3).

Chung, Byung Hun. (2017) Do differences in national cultures affect cross-country financial s statement comparability under IFRS?." PhD (Doctor of Philosophy) thesis, University of Iowa, 2017.

Dahawy, K., Merino, B.D., Conover, T.L (2002).The conflict between IAS disclosurer requirements and the secretive culture in Egypt. Advances in International accounting. 15 .pp.203-228.

Dahawy, K., Shehata, N.F, Ransopher, T.D (2014). The state of accounting in Egypt : A case. Journal of Business Cases and Applications, 3.

Dakhli, A. (2009), Budgetary Participation, Locus Of Control And Job Satisfaction In Tunisia (No. halshs-00459229).

Dalci, I., \& Ozyapici , H. (2018). Cultural values and students` intentions of choosing accounting career. Journal of Financial Reporting and Accounting, 16 (1), 179-196

Damak, S \& Ben Salem, R. (2012). La culture et le recours aux IAS/IFRS, La Revue des Sciences de Gestion, $\mathrm{N}^{\circ}$ 254.pp.39-48.

Dedoussis, E. (2004). A cross-cultural comparison of organizational culture: evidence from universities in the Arab world and Japan. Cross Cultural Management, 11(1), 15-34

Doupnik, S. T, Gotti, G, Kang, T, \& Salter, S. B (2010). The Influence of Culture on Accounting Conservatism. American Accounting Association Annual Meeting San Francisco, $C A$

Doupnik, T, Riccio, E.1, (2006). The influence of conservatism and secrecy on the interpretation of verbal probability expressions in the Anglo and Latin cultural areas. The International Journal of Accounting, 41, 237-261.

Doupnik, T \& Richter, M (2003). The impact of culture on the interpretation of "in context" verbal probability expressions. Journal of International Accounting Research. 
Dowa. A., Elgammi., A, Elhttab., A. S and Mutat., H (2017). Main Worldwide Cultural Obstacles on Adopting International Financial Reporting Standards (IFRS). International journal of economics and finance, vol 9.

Du, N, Stevens, K (2011). Numeric-to-verbal translation of probability expressions in SFAS 5, Managerial Auditing Journal, Vol. 26 Iss: 3, pp.248 - 262

Du. N, Stevens. K, Ahern.J \& Shigaev.A (2016).Cross-cultural Differences in Interpre.K, ting IAS 37 Probability Phrases, International Journal of Financial Research. vol. 7(1), pages 1-8.

Eddie, I.A, (1990). Asia Pacific Cultural Values and Accounting Systems. Asia Pacific International Management Forum, 16

El Akremi, A., IkramNasr, M., \& Sassi, N. (2007), Impact de la culture nationale sur la confiance interpersonnelle en milieu du travail: analyse comparative entre la France et la Tunisie. Les actes du 18 ème congrès AGRH, Fribourg, Suisse.

El Louadi, M. (2004), Cultures et communication électronique dans le monde arabe, Systèmes d'Information et Management, Vol. 9 No .3, 117-143.

Emenyonu, E.N, \& Gray, S.J (1996). International accounting harmonization and the major developed stock market countries: An empirical study. The International Journal of Accounting, 31(3), pp. 269-279.

Fernandez, D.R, Carlson, D. S, Stepina, L.P \& Nicholson, J.D, (1997). Hofstede's Country classification 25 years later. The Journal of Social Psychology. 137(1) pp.43- 54.

Gaballa, A.S.M and Ning, Z (2011). An analytical study of the effects of the experience on the performance of the external auditor. International conference on Business and economic research. vol1. IACSIT. Kuala Lumpur, Malaysia.

Gray, S, J. (1988). Towards a theory of cultural influences on the development of accounting systems internationally. ABACUS. 24(1).1-15.

Gray, S.J and Vint, H.M (1995). The Impact of Culture on Accounting Disclosures: Some International Evidence. Asia-Pacific Journal of Accounting 21: 33-43.

Gregory, A.L and Markus J.M (2005).Comparing the investment decisions of accounting practitioners and students: an empirical study on the adequacy of student surrogates. Accounting Forum. Vol 29 (2).pp121-135

Gruning. M. (2007). Drivers of corporate disclosure: A structural equation analysis in a Central European setting. Management Research News. 30(9). 646-660

Geurmezi, W and Hlioui, K. (2019) Do differences in national cultures affect cross-country conditional conservatism behavior under IFRS. Research In international Business and Finance. Vol (9) 
Haller, A \& Wehrfritz,M, (2014). The impact of national GAAP and accounting traditions on IFRS policy selection: Evidence from Germany and the UK Journal of International Accounting, Auditing and Taxation. 22 .39-56

Harris, A.J.L \& Corner, A. (2011). Communicating Environmental Risks: Clarifying the Severity Effect in Interpretations of Verbal Probability Expressions. Journal of Experimental Psychology :Learning, memory and cognition.37 (6).1571- 1578.

HassabElnaby, H.R, Epps, R.,W, Said, A.A (2003). The impact of environmental factors on accounting development : an Egyptian longitudinal study. Critical perspectives on accounting. 14(3). pp.273-292.

Hassan, M.,K. (2008). The development of accounting regulation in Egypt: Legitimating the international accounting standards. Managerial auditing journal. 23 (5). pp.467-484.

Heidhues, E and Patel. C (2009). IFRS and exercise of accountants' professional judgment: Insights and concerns from a German perspective. IAAER international association for accounting education and research. International accounting congress. Sao Paolo, Brazil.

Hofstede, G. (2001). Culture Consequences: Comparing Values, behaviours, Institutions and Organizations across nations. Sage publications.

Houghtonm K.A and Hronsky, J.F (1993). The sharing of meaning between accounting students and members of the accounting professions. Accounting and Finance. Vol 33 (2).pp.131-147.

Hu. C, Chand . P and Evans. E (2013) The Effect of National Culture, Acculturation, and Education on Accounting Judgments: A Comparative Study of Australian and Chinese Culture. Journal of International Accounting Research. 12(2). 51-77.

Hussein,. M.E. (1996). A Comparative Study of Cultural Influences on Financial Reporting in the U.S and the Netherlands. The International Journal of Accounting. 31(1): 95-120.

Huerta, E. Petrides, Y. \& Brau, G.P (2016). Interpretation of probability expressions in accounting. Journal of International Accounting, Auditing and Taxation. 27. p. 1-12

International Financial Reporting Standards /Tunisia. retrieved on 19/10/2013 from http://www.estandardsforum.org/tunisia/standards/international-financial- reporting-standard.

Iskandar, T.M and Pourjalali, H (2000). Cultural Influence on the Development of Accounting Practices in Malaysia. Asian Review of Accounting, 8(2), pp. 1-31

Jaggi, B \& Lowy, P.Y (2000). Impact of Culture, Market Forces, and Legal System on Financial Disclosures. The International Journal of Accounting, 35(4), pp.495-519

Kholeif, A. O.R (2010). A New Institutional Analysis of IFRS Adoption in Egypt: A 
Case Study of Loosely Coupled Rules and Routines. Research in Accounting in

Emerging Economies. 10. pp.29.

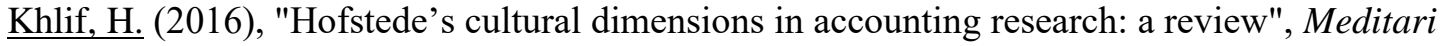

Accountancy Research, Vol. 24 No. 4, pp. 545-573.

Khlif, H \& Achek, I (2017). Gender in accounting research: A review. Managerial Auditing Journal. 32

(6). pp. 627-655.

Kinsey, J.P; Hood, A.C and Boyar, S (2018). Implications for IFRS Principles-Based and U.S. GAAP Rules-Based Applications: Are Accountants' Decisions Affected by Work Location and Core Self-Evaluations? Journal of international Accounting Auditing and Taxation.Vol 32

Klibi, M.F and Oussi, A.A (2013). Skills and attributes needed for success in accounting career : Do employers' expectations fit with student' perceptions? Evidence from Tunisia. International Journal of Business and Management. (8).pp118-132.

Marcelino, M.M (2016). The influence of culture and professional judgement on Accounting: An analysis from the perspective of information preparers in Portugal. Journal of education and research in accounting. 10 (1).pp.63-87.

Marshall Hunt, D. and At-Twaijri, M.I. (1996), "Values and the Saudi manager: an empirical investigation", Journal of Management Development, Vol. 15 No. 5, pp. 48-55.

May C, Finch T. (2009). Implementing, Embedding, and Integrating Practices: An Outline of Normalization Process Theory. Sociology. 2009;43(3):535-554.

Mokhtar, E.S (2016). A study of IFRS-based Uncertainty Expressions : The case of Middle East Region. Accouting Thought, Ain Chams University (4).

Mouritsen, J (1989). Accounting Culture and Accounting-Culture. Scandinavian Journal of Management, Vol 5 (1), 21-47

Naser, K., AlKhayal,T., Nuseibah,R.,\& AlTaweel,I.(2005). Users' opinions about different aspects of accounting harmonization: Evidence from the Gulf Co-operation Council (GCC). IJCM, 15 (3\&4), 272-299.

Nalukenge, I., Nkundabanyanga, S.K. and Ntayi, J.M. (2018), "Corporate governance, ethics, internal controls and compliance with IFRS", Journal of Financial Reporting and Accounting, Vol. 16 No. 4, pp. $764-786$

Nurunnabi, M (2014). “Does Accounting Regulation Matter?”: An experience of international accounting standards implementation in an emerging country. Research in Accounting regulation.

Nurunnabi, M, Jermakowicz,E.K and Donker,H. (2020) Implementing IFRS in Saudi Arabia: evidence from publicly traded companies, international Journal of Accounting and Information managment, 28, (2), 243-27

Omri, M.A and Akrimi, N. (2011) 'The preparedness of listed Tunisian companies to adopt international financial reporting standards', International. Journal of Accounting, Auditing and Performance Evaluation, Vol. 7, No. 3, pp.253-265. 
Oussii, A.A. and Klibi, M.F. (2017), "Accounting students' perceptions of important business communication skills for career success: An exploratory study in the Tunisian context", Journal of Financial Reporting and Accounting, Vol. 15 No. 2, pp. 208-225

Patel, C., Harrison,G. L., \& McKinnon, J.L. (2002). Cultural Influences on Judgments of Professional Accountants in Auditor-Client Conflict Resolution. Journal of international financial management and accounting, 13. 1-31.

Salleh, S.M, Gardner, J,C, Sulong.Z, McGowan, Jr. C.B (2011). The interpretation of "in context" verbal probability expressions used in International Accounting Standards: A comparison of English and Chinese students studying at English speaking universities, The 2011 New Orleans International Academic Conference.

Simon, J. (2002), “Interpretation of Probability Expressions by Financial Directors and Auditors of UK Companies". The European Accounting Review, Vol. 11(3). pp. 601-629.

Shigufta H. U., (2016), "Cost-benefit analysis of IFRS adoption: developed and emerging countries", Journal of Financial Reporting and Accounting, Vol. 14 No. 2, pp. 198-229.

Schultz, J \& Lopez, T (2001). The Impact of National Influence on Accounting Estimates Implications for International Accounting Standard-Setters'. The International Journal of Accounting, 36(3), pp. 271-190.

Sikkema, S.E. and Sauerwein, J.A. (2015), "Exploring culture-specific learning styles in accounting education", Journal of International Education in Business, Vol. 8 No. 2, pp. 78-91

Tang, F and Yang, L (2016). The interpretation differences of verbal probability expressions in principles-based accounting standards: Evidence from China. International Journal of Accounting Auditing and performance evaluation. 12(3):287

Teixeira, C \& Fialho, S. (2009). 'The Interpretation of Verbal Probability Expressions Used in the IAS/IFRS: Some Portuguese Evidence, Polytechnical Studies Review. Vol VII, nº 12, 057-073.

Triki, M., and Bouaziz, Z. (2012). The impact of the Board of directors on the financial performance of Tunisian companies.https://mpra.ub.uni-muenchen.de/38672/

Trottier, K and Gordon, I.M (2018). Students as surrogates for managers : Evidence from a replicated experiment. Canadian Journal of Administrative sciences. Vol35. Pp. 146-161

Tsakumis, G.T (2007). 'The Influence of Culture on Accountants' Application of Financial Reporting Rules'. ABACUS, 43(1).

Union of Certified Accouontants in Tunisia (2009). Adoption des Normes Comptables Internationales IAS/IFRS: Avantages et Contraintes d'Application. Retrived from http://www.uec.com.tn/files/pdf/Adoption des normes IFRS.pdf on 18/1/2011.

Waldron,M and Fisher, R (2017). Values and ethical judgments: The adequacy of students as surrogates for professional accountants. Meditari Accountancy Research, Vol. 25 Issue: 1, pp.37-6

Ward, C. L.; Lowe, S.K, (2017). Cultural impact of international financial reporting standards on the comparability of financial statements. International Journal of Business, Accounting, \& Finance. Vol 11 (1),p46-56.

Yamani., A. and Almasarwah,, A. (2019), "Resistive factors of delaying IFRS adoption in Saudi Arabia 
listed firms", Journal of Financial Reporting and Accounting, Vol. 17 No. 3, pp. 468-497.

Zhang, Y., De Zoysa, A; and Cortese, C. (2019). Uncertainty Expressions in Accounting: Critical Issues and Recommendations, Australasian Accounting, Business and Finance Journal, 13(4), 2019, 4-22. 